\title{
Effects of roughing on finish rolling simulations in microalloyed strip steels
}

\author{
Chalimba S.A.J., Mostert R.J., Stumpf W.E., Siyasiya C.W., Banks K.M. \\ Department of Materials Science and Metallurgical Engineering, University of Pretoria, Hatfield, \\ Pretoria, Republic of South Africa \\ Corresponding author: Tel: +27 606033216 \\ Email: stephenchalimba@yahoo.com
}

\begin{abstract}
The effects of a roughing pass in hot rolling simulations were assessed in VN and $\mathrm{Nb}$-Ti steels. Continuous cooling phase transformation temperatures, flow curves, softening mechanisms (dynamic transformation DT and dynamic recrystallization DRX), and deformed microstructure morphologies were analysed. The application of one or more roughing passes eliminates the effects of prior microstructural history, and ensures that all stock material experiences equivalent hot working conditions and state of the microalloying elements. It has been shown that roughing in hot simulation has the following positive influences: 1) provides more reliable flow stress data; 2) gives greater consistencies and accuracy in analysis of softening mechanisms giving three distinct regimes (DT regime at temperatures below $800{ }^{\circ} \mathrm{C}$, DT/DRX inter-mode regime between 800 and $950{ }^{\circ} \mathrm{C}$ and $\mathrm{DRX}$ regime for temperatures above $950{ }^{\circ} \mathrm{C}$ for $\mathrm{VN}$ steel); 3) promotion of softening mechanisms as evidence by low critical strains $\left(\varepsilon_{c D T}\right.$ was within the range 0.08 to 0.12 while for Finishing only pass, the $\varepsilon_{c D T}$ was in the range of 0.11 to 0.14 at $\dot{\varepsilon}=0.1 \mathrm{~s}^{-1}$; 4) for Roughing and Finishing schedules, DT was verified to occur at temperatures $117^{\circ} \mathrm{C}$ and $133^{\circ} \mathrm{C}$ above $A e_{3}$ for $\mathrm{VN}$ steel and $\mathrm{Nb}$-Ti steel, respectively, compared to the $\mathrm{F}$ only schedules which showed that DT can only occur at temperatures below the $\mathrm{Ae}_{3}$; 5) RF schedules promoted uniform microstructural morphologies compared to inhomogeneous microstructures realised in F-only schedules.
\end{abstract}

Key words: dynamic transformation, dynamic recrystallization, critical strain, roughing, finishing, hot rolling

\section{Introduction}

Hot working simulations provide a basis for flow behaviour studies at elevated temperatures, which include modelling of thermo-mechanical process parameters such as flow stress, work-hardening and softening mechanisms, and accompanied microstructural evolution [1]. Hot workability simulation tests may include: uniaxial axisymmetric compression, plane strain compression, torsion, tensile, and indentation tests - the most commonly used being axisymmetric compression and torsion testing [2, 3]. The lack of internationally recognised standard test methods leads to variations in testing conditions or approaches and care should be taken in comparing test data results or application of the various models developed for hot working.

Hot workability of steels is affected by intrinsic factors that include the initial microstructure and prior processing history [4], which should be considered in test method development to ensure consistent and accurate results. Comparing the 
axisymmetric compression and torsion testing methods, a notable difference in most test schedules is the inclusion of an austenite roughing pass in hot torsion tests $[5,6$, $7,8,9]$ which is frequently absent in hot compression tests $[10,11,12,13,14]$. This exclusion in the latter is mostly attributed to total strain limitation due to frictional effects and barrelling.

During hot strip rolling, the roughing strain promotes grain refinement through recrystallization at high temperatures greater than $1000^{\circ} \mathrm{C}$ [15]. In microalloyed steels, the transfer time between roughing and finishing trains also promotes full recrystallization when there is sufficient time and the transfer bar temperature exceeds the nil-recrystallization temperature, $T_{\mathrm{nr}}[15,16,9]$. Prolonged transfer periods, however, may lead to precipitation, grain growth and coarsening.

As far as is discernible, no attention has been given to how this lack of roughing in hot compression tests affects hot working simulations and modelling. This study, therefore, investigates the effects of inclusion of a roughing pass in finish rolling simulation tests with the ultimate objective of generating repeatable test data for use in modelling the flow behaviour and its concomitant microstructural evolution.

\section{Experimental procedure}

The VN and $\mathrm{Nb}-\mathrm{Ti}$ microalloyed steels with chemical compositions given in Error! Reference source not found. were studied. For the VN steel a vacuum induction melted ingot was hot rolled to $13 \mathrm{~mm}$ diameter bar, whilst the $\mathrm{Nb}$-Ti steel specimens were machined from an as-cast industrial billet. Axisymmetric hot compression specimens were machined to a height of $15 \mathrm{~mm}$ and diameter of $10 \mathrm{~mm}$, and for VN steel specimens were machined parallel to the rolling direction. An aspect ratio of 1.5 was maintained on specimens to minimize sample geometry influence on test results. Dilatometry specimens were machined to a height of $10 \mathrm{~mm}$ and a diameter of $5 \mathrm{~mm}$.

\section{Error! Reference source not found.}

\begin{tabular}{llllllllll}
\hline \multirow{2}{*}{ Steel } & \multicolumn{10}{c}{ Element } \\
\cline { 2 - 10 } & $\mathbf{C}$ & $\mathbf{M n}$ & $\mathbf{S i}$ & $\mathbf{A l}$ & $\mathbf{N b}$ & $\mathbf{T i}$ & $\mathbf{V}$ & $\mathbf{N}$ & $\mathbf{F e}$ \\
\hline VN & 0.06 & 1.69 & 0.29 & 0.049 & 0.0015 & Trace & 0.062 & 0.0097 & Bal. \\
Nb-Ti & 0.09 & 0.88 & 0.20 & 0.043 & 0.025 & 0.017 & 0 & 0.0088 & Bal. \\
\hline Note: LECO® analysis was used in the determination of C and N & & & \\
\hline
\end{tabular}

A Gleeble ${ }^{T M} 1500$ thermomechanical simulator fitted with tungsten carbide (WC) anvils was used for the isothermal axisymmetric uniaxial compression tests under Argon using a K-type thermocouple and quenching with Helium. Microstructure analyses were performed at the centre of an axially-sectioned plane of the specimens.

The roughing and finishing (RF), and finishing-only (F-only) schedules are shown schematically in 


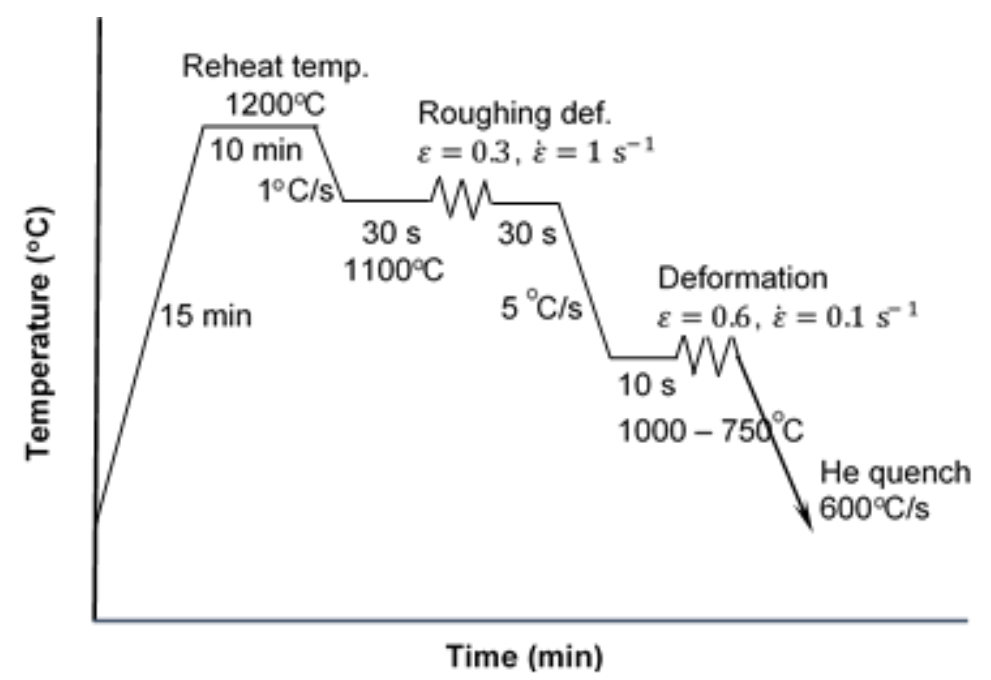

a)

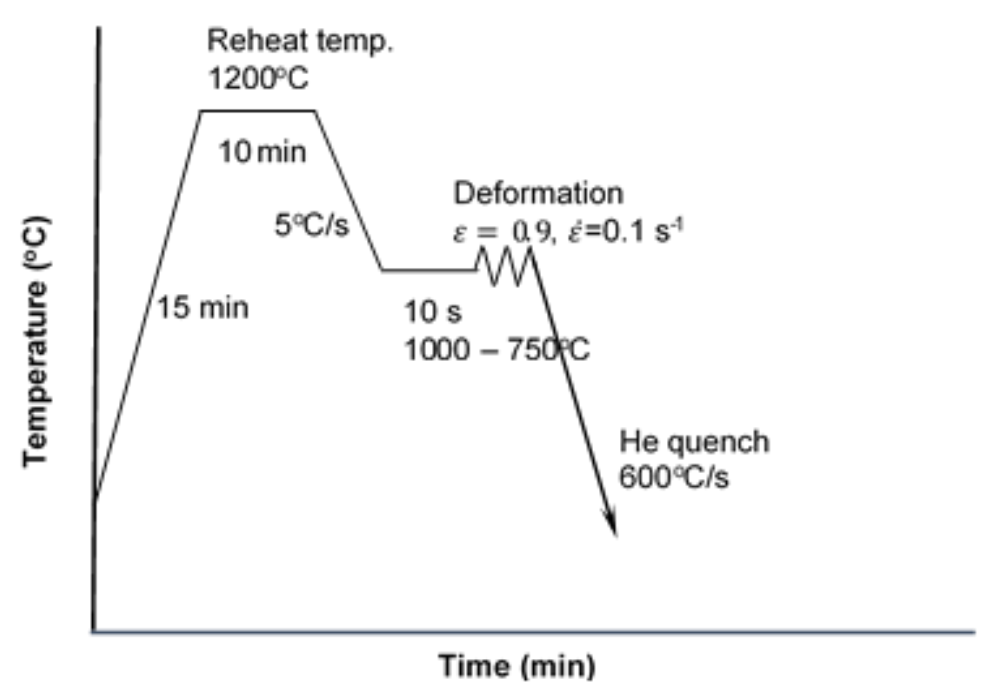

b)

Figure 1a) and b), respectively. Normally a roughing pass with a strain in the range of 0.3 to 0.5 at a strain rate of $1 \mathrm{~s}^{-1}$ is applied in most hot torsion tests with a post deformation delay of between $30 \mathrm{~s}$ to 2 min in microalloyed steels $[9,5]$. A typical austenitization temperature of $1200{ }^{\circ} \mathrm{C}$ was applied in all tests. According to the ThermoCalc $\AA 4.1$ property diagrams using the Steel and Iron Alloys Database TCFE7, the austenisation temperature exceeded the dissolution temperature for both $\mathrm{V}(\mathrm{C}, \mathrm{N})-854^{\circ} \mathrm{C}$ and $\mathrm{Nb}(\mathrm{C}, \mathrm{N})-1092^{\circ} \mathrm{C}$. 


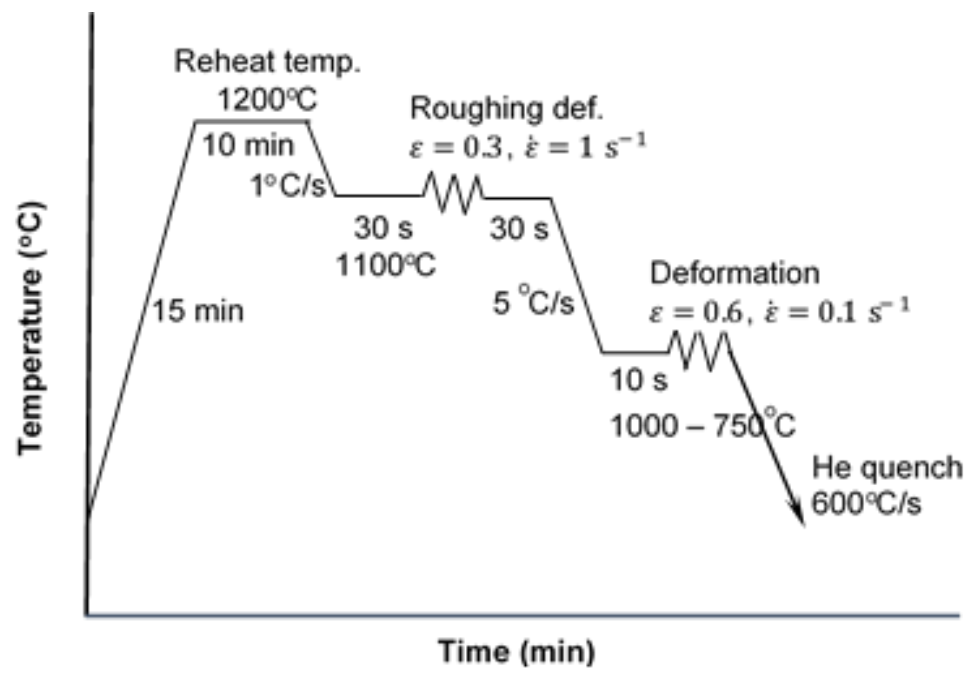

a)

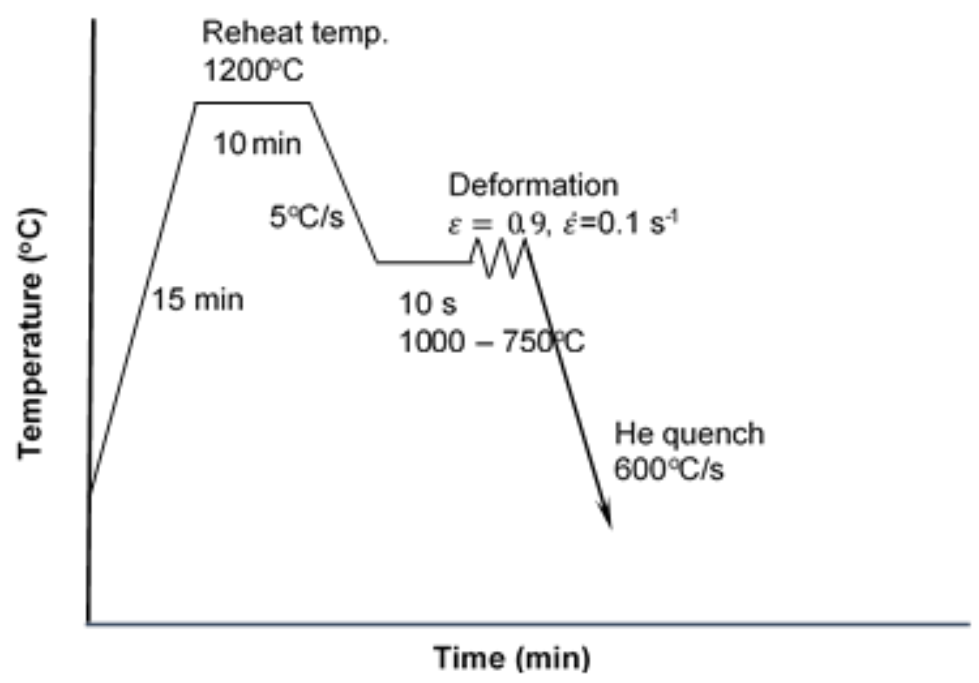

b)

Figure 1 - Schematic representation of a) roughing and finishing (RF) and b) finishing-only (F-only) test schedules. True strain and strain rate are represented as $\varepsilon$ and $\dot{\varepsilon}$ respectively.

An inductive-heating Bähr ${ }^{\mathrm{TM}} 805 \mathrm{AD}$ quenching and deformation dilatometer was used to determine the continuous cooling critical transformation temperatures at varying cooling rates for both $\mathrm{RF}$ and F-only specimens. The dilatation curves were also used to determine the ferrite volume fractions at the start of the finishing pass. For RF specimens, continuous cooling transformation curves were obtained after the roughing at $1100{ }^{\circ} \mathrm{C}$ in 


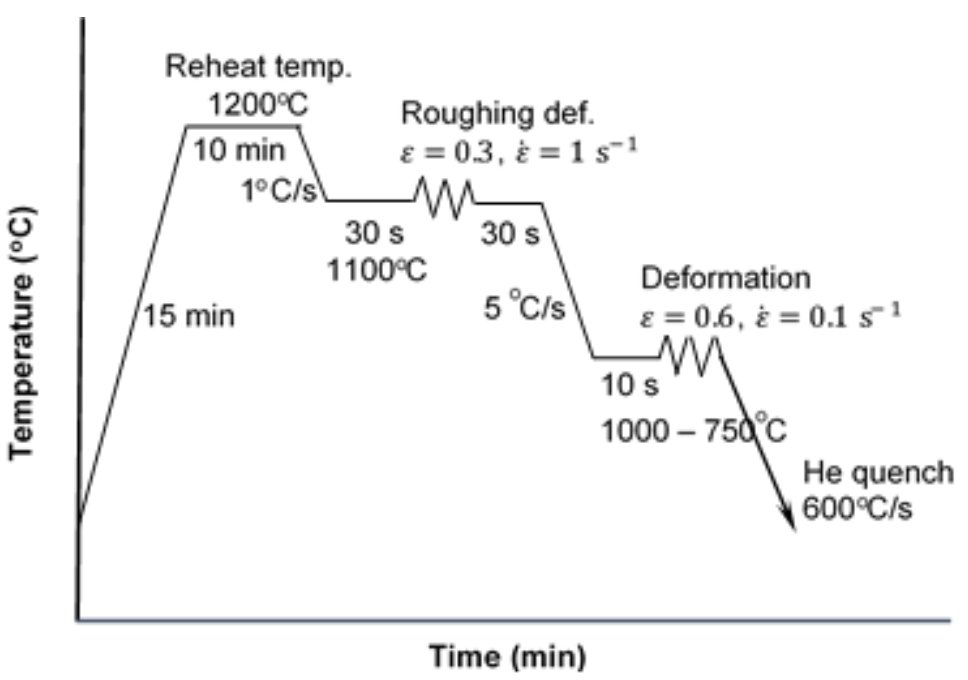

a)

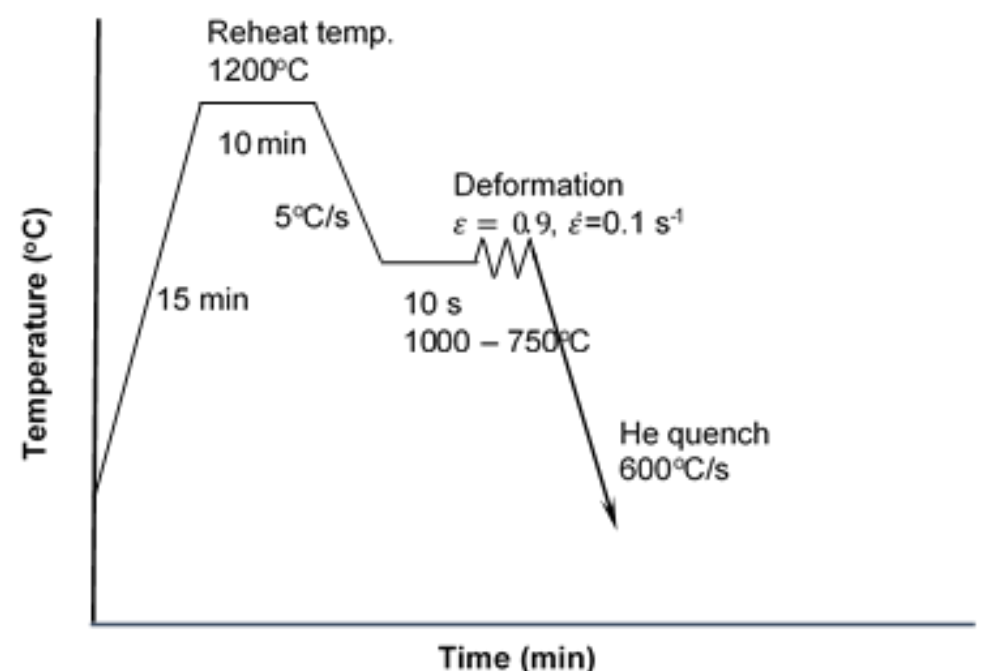

b)

Figure 1a), while for F-only specimens, similar curves were obtained after austenitization at $1200^{\circ} \mathrm{C}$ in

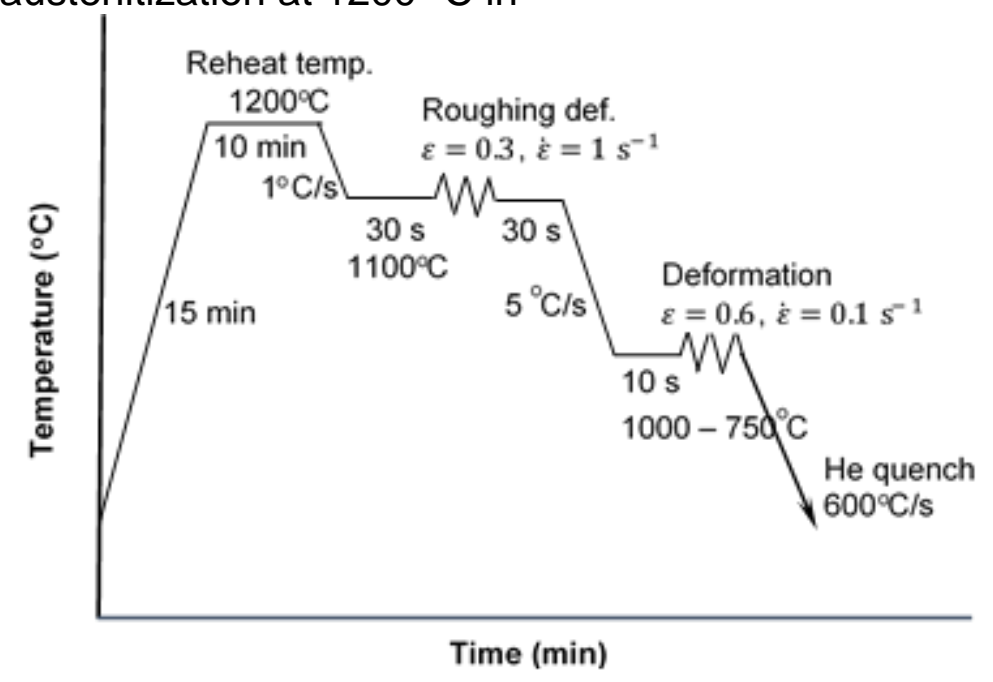

a) 


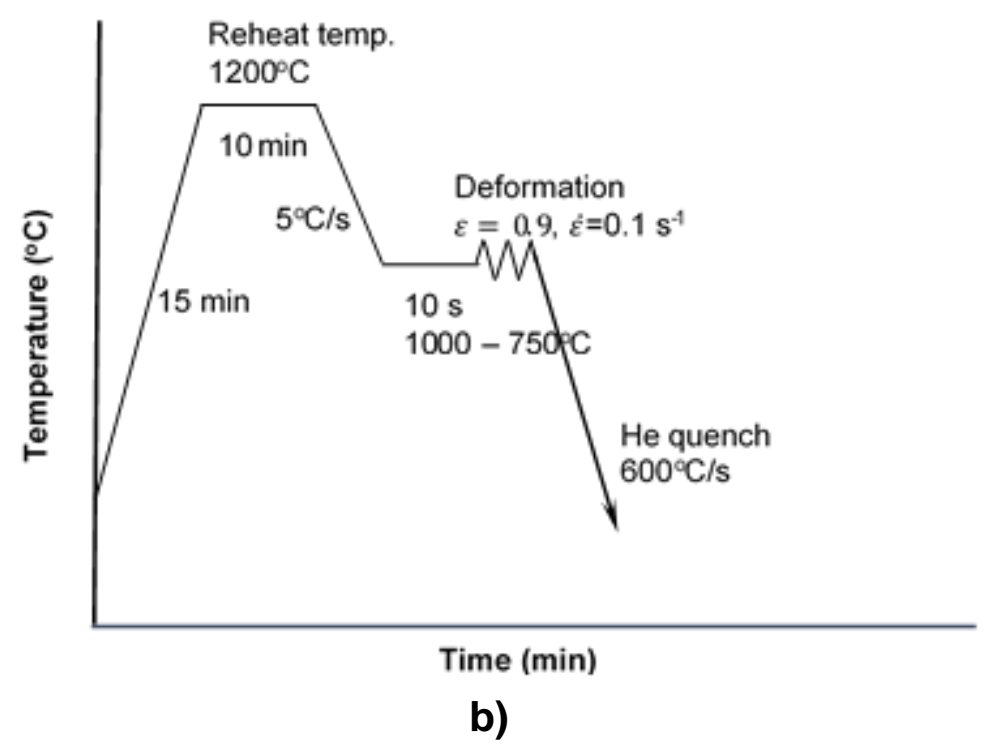

Figure 1b).

The onset of DT and DRX was determined by the double differentiation method which requires that the local stored energy in the deformed material attains a maximum critical value while the rate of dissipation must decrease to a minimum value [17]. This condition is expressed mathematically as:

$$
\frac{\partial}{\partial \varepsilon}\left(-\frac{\partial \ln \theta}{\partial \varepsilon}\right)=0
$$

The critical strains for initiation of dynamic transformation $\left(\varepsilon_{c D T}\right)$ and DRX $\left(\varepsilon_{C D R X}\right)$ were determined by inflections on the $\ln \theta-\varepsilon$ plots, where $\theta$ is the work-hardening rate. The critical strains are given as the single minima in $\partial \ln \theta / \partial \varepsilon$ versus $\varepsilon$ plots, representing $\varepsilon_{C D T}$ and $\varepsilon_{C D R X}$ at low and high temperatures respectively or $\varepsilon_{C D T}$ followed by $\varepsilon_{C D R X}$ for double minima plots at intermediate temperatures. The rate of progression of DT and DRX was also assessed from the slope of $d \ln \theta / d \varepsilon$ versus $\varepsilon$ plots. This method enabled the determination of critical strains by fitting sixth-order polynomials compared to the commonly used $\theta$ versus $\sigma$ curves that require fitting of ninth- or higher order polynomials $[18,19]$. The method was also considered more appropriate for determination of critical strains considering its higher correlation coefficients than $\theta$ versus $\sigma$ plots $[13,17]$. The curves were fitted to the macroscopic work-hardening flow curve determined using the $2 \%$ offset strain method [20].

\section{Results}

\section{Dilatometry experiments}

Dilatation curves for both RF and F-only specimens were plotted at various cooling rates i.e. quasi-equilibrium $0.05^{\circ} \mathrm{C} / \mathrm{s}$, and accelerated cooling rates of 5 and $20^{\circ} \mathrm{C} / \mathrm{s}$. A summary of the critical transformation temperatures at various cooling rates for both RF and F-only specimens are shown in Error! Reference source not found..

Error! Reference source not found.

\begin{tabular}{|c|c|c|c|c|c|c|c|}
\hline \multirow{2}{*}{ No } & \multirow{2}{*}{ Steel } & \multirow{2}{*}{ Roughing } & Cooling rate, $\dot{\theta}$ & $A e_{3}$ & $A r_{3}^{*}$ & $A r_{3}$ & $A r_{1}$ \\
\hline & & & $\left({ }^{\circ} \mathrm{C} / \mathrm{s}\right)$ & ${ }^{\circ} \mathrm{C}$ & ${ }^{\circ} \mathrm{C}$ & ${ }^{\circ} \mathrm{C}$ & ${ }^{\circ} \mathrm{C}$ \\
\hline 1 & $\mathrm{VN}$ & Yes & 20 & 833 & 851 & 832 & 518 \\
\hline
\end{tabular}




\begin{tabular}{|c|c|c|c|c|c|c|c|}
\hline 2 & VN & Yes & 5 & & & 843 & 540 \\
\hline 3 & VN & Yes & 0.05 & & & 906 & 693 \\
\hline 4 & VN & No & 20 & & & 719 & 483 \\
\hline 5 & VN & No & 5 & & 820 & 821 & 537 \\
\hline 6 & VN & No & 0.05 & & & 828 & 700 \\
\hline 7 & $\mathrm{Nb}-\mathrm{Ti}$ & Yes & 20 & & & 820 & 568 \\
\hline 8 & $\mathrm{Nb}-\mathrm{Ti}$ & Yes & 5 & & 932 & 818 & 616 \\
\hline 9 & $\mathrm{Nb}-\mathrm{Ti}$ & Yes & 0.05 & & & 968 & 713 \\
\hline 10 & $\mathrm{Nb}-\mathrm{Ti}$ & No & 20 & 801 & & 747 & 538 \\
\hline 11 & $\mathrm{Nb}-\mathrm{Ti}$ & No & 5 & & 890 & 794 & 598 \\
\hline 12 & $\mathrm{Nb}-\mathrm{Ti}$ & No & 0.05 & & & 936 & 734 \\
\hline
\end{tabular}

Note: $A e_{3}$ is the upper equilibrium temperature between ferrite and austenite, $A r_{3}^{*}$ is the upper critical temperatures for deformed austenite, $\mathrm{Ar}_{3}$ is the continuous cooling ferrite transformation start temperature, and $A r_{1}$ is the actual continuous cooling proeutectoid ferrite transformation finish temperature.

\section{Flow curve behaviour}

Figure 2 shows the flow stress curves of both RF and F-only specimens deformed to a true strain of 0.6 and 0.9 , respectively and at different temperatures as per deformation schedule given in

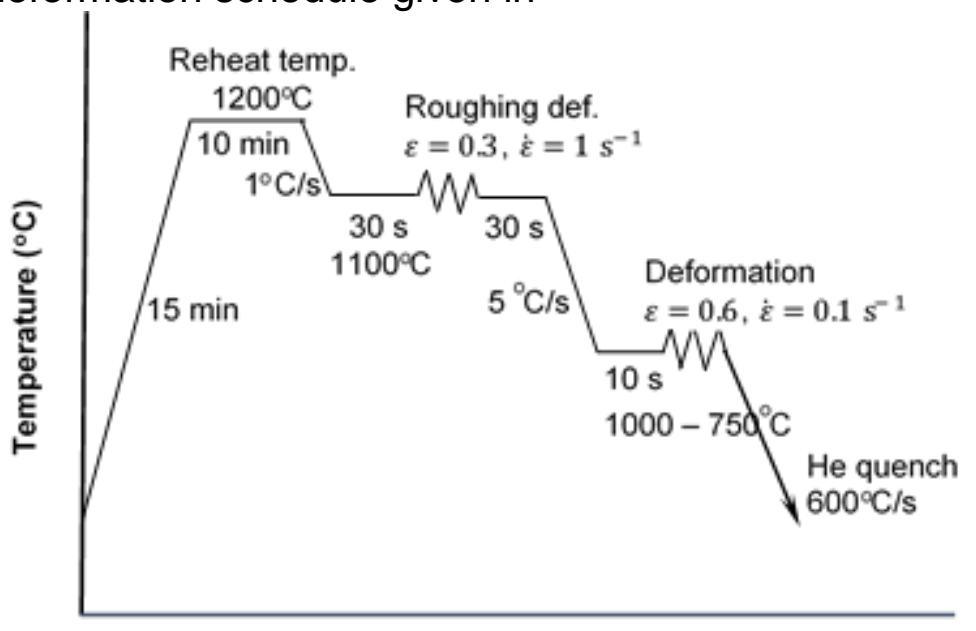

Time (min)

a)

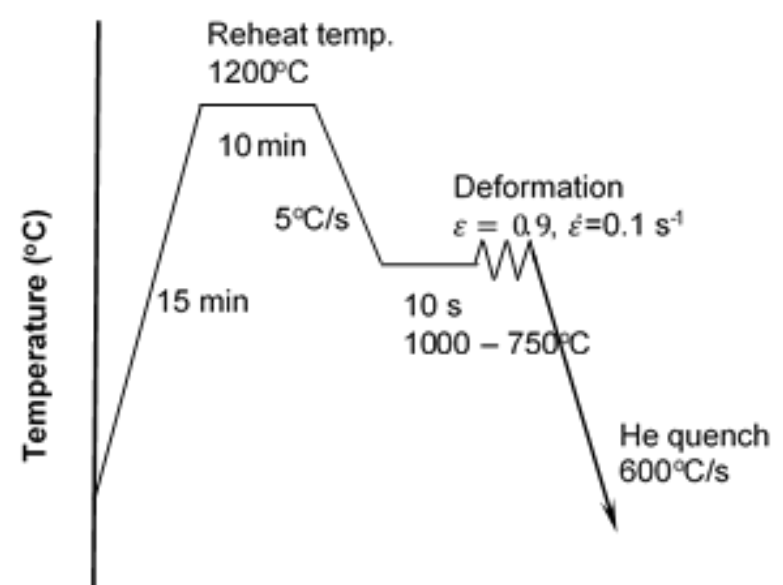

Time ( $\mathrm{min})$

b) 
Figure 1. It should be noted that the total true strain in both cases is 0.9 , i.e. a roughing strain of 0.3 followed by a finishing strain of 0.6 were applied to RF specimens. From the dilatometry results, both materials are fully austenitic at the onset of finishing, except at $800^{\circ} \mathrm{C}$ and below. For VN steel, the austenite volume fraction at 750 and $800{ }^{\circ} \mathrm{C}$ was $85 \%$ and $>95 \%$ respectively, whilst for $\mathrm{Nb}-\mathrm{Ti}$ steel the austenite volume fraction at $750{ }^{\circ} \mathrm{C}$ was $80 \%$ and $100 \%$ at $800{ }^{\circ} \mathrm{C}$. 

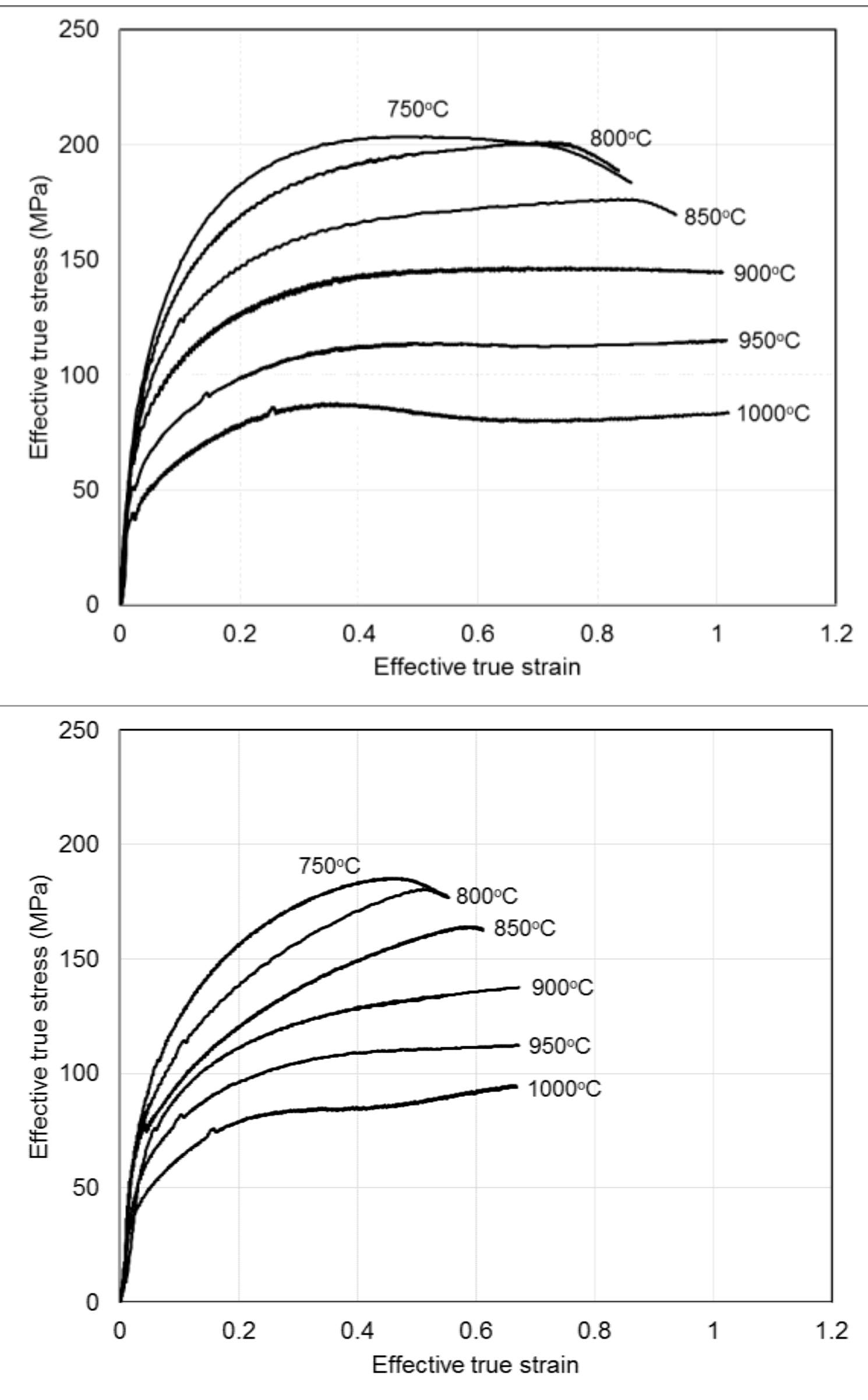

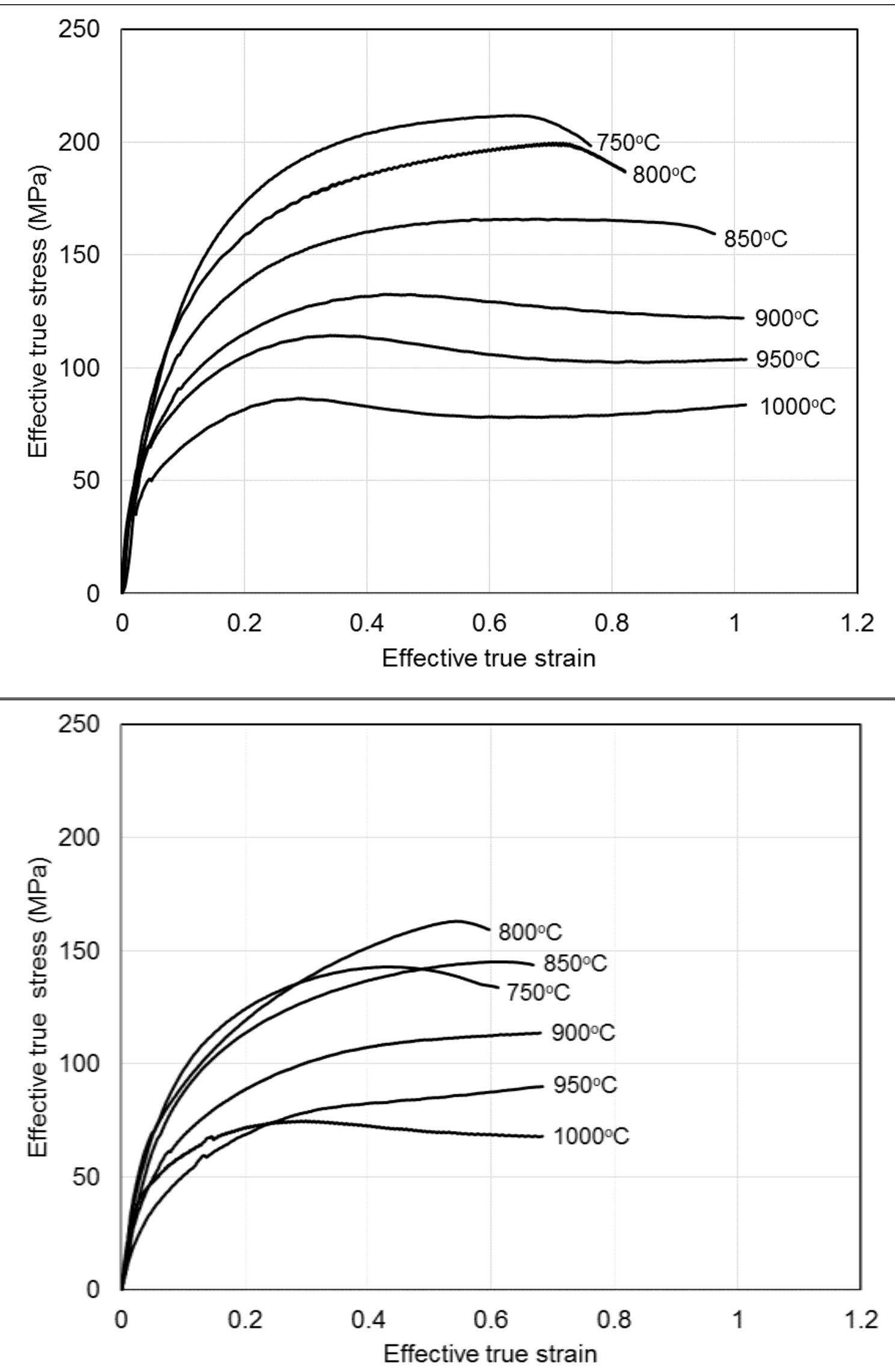

Figure 2 - Flow curves for VN steel and Nb-Ti for RF and non-F-only specimens at $\dot{\varepsilon}=0.1 \mathrm{~s}^{-1}$ 
The stress-strain curves show the usual hot deformation tendency of an increase in flow stress with decreasing temperature except at $750{ }^{\circ} \mathrm{C}$, which is below the $A r_{3}$ temperature in the two-phase region for RF VN steel curves (i.e. lower stress levels are attributed to the presence of softer ferrite).

Flow curve type: The flow stress curves may be classified into the following three types:

1. DRX type - where a peak stress $\left(\sigma_{p}\right)$ is attained followed by a lower steady state stress at higher temperatures where DRX is the only softening mechanism;

2. DRX/DT mixed mode - which shows continuous work-hardening throughout the deformation at intermediate temperatures, further which a saturated stress can be achieved as in DRV type curves; and

3. DT type - where at lower temperatures due to ferrite formation during deformation, there is an appreciable decrease in stress levels after $\sigma_{p}$ is attained.

A notable difference in the RF curves is that only the $1000{ }^{\circ} \mathrm{C}$ flow curve shows the typical DRX shape, while at 900 and $950{ }^{\circ} \mathrm{C}$ flow curves are DRX/DT mixed mode shaped followed by lower temperature curves between 750 and $850^{\circ} \mathrm{C}$, that indicate DT taking place. F-only tests have a DRX shape for temperatures above $850{ }^{\circ} \mathrm{C}$ and a DT curve shape at temperatures of $850^{\circ} \mathrm{C}$ and lower.

Softening behaviour analysis: A plot of $\sigma_{p}$ against temperature in Figure 3 indicates that significant softening occurs for the RF condition below $850^{\circ} \mathrm{C}$. Further analysis of the softening mechanisms was done by studying Boratto diagrams (MFS versus inverse absolute temperature plots) given in Figure 4 where the inflections on the plots were used to i) study the progress of softening, ii) determine the apparent nil-recrystallization temperature $\left(T_{n r}{ }^{*}\right)$, and iii) determine the upper critical temperatures for deformed austenite $\mathrm{Ar}_{3}^{*}$, see Error! Reference source not found..

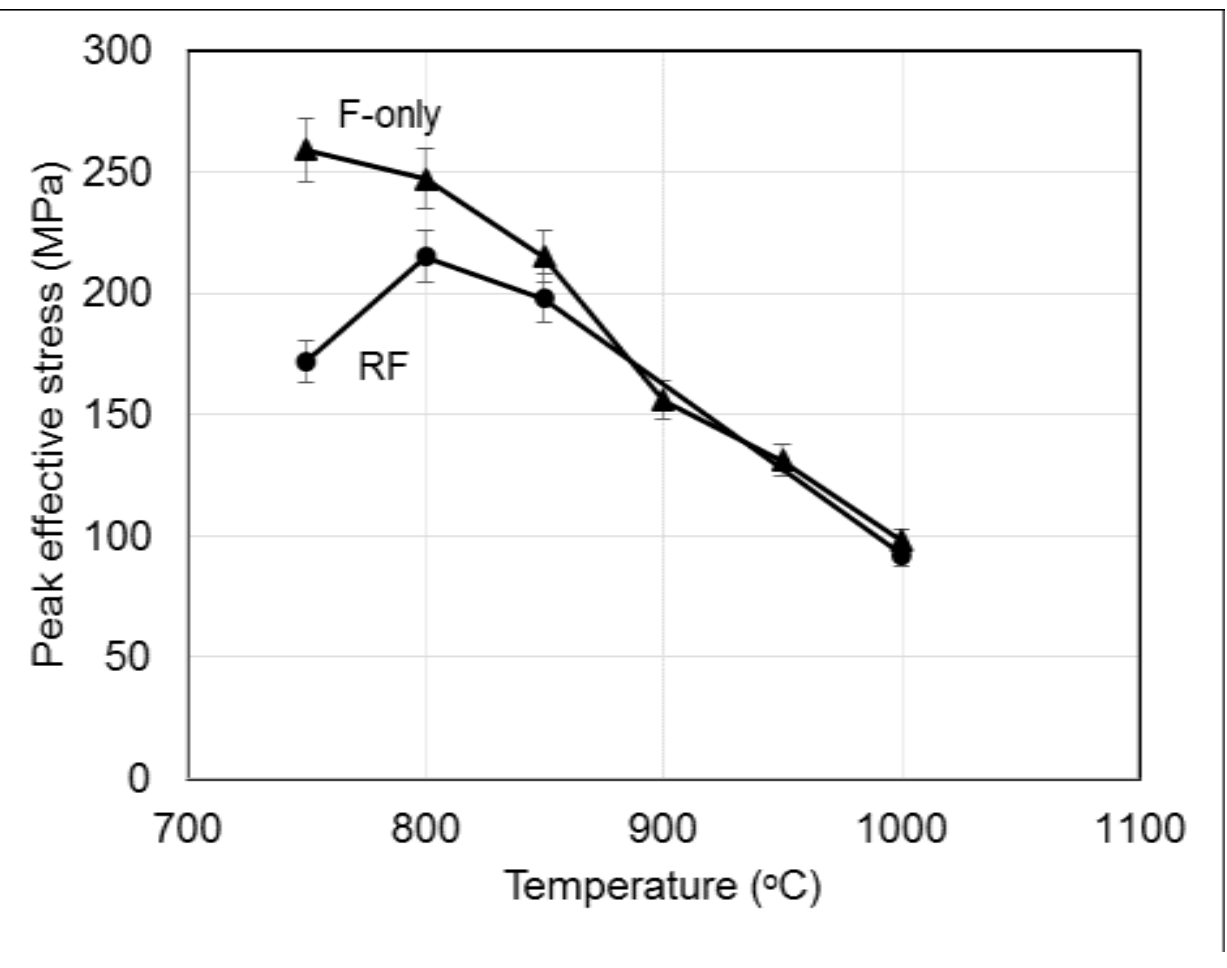

Figure 3 - VN steel peak stress $\left(\sigma_{p}\right)$ versus temperature plot at a $\dot{\varepsilon}=0.1 \mathrm{~s}^{-1}$ 


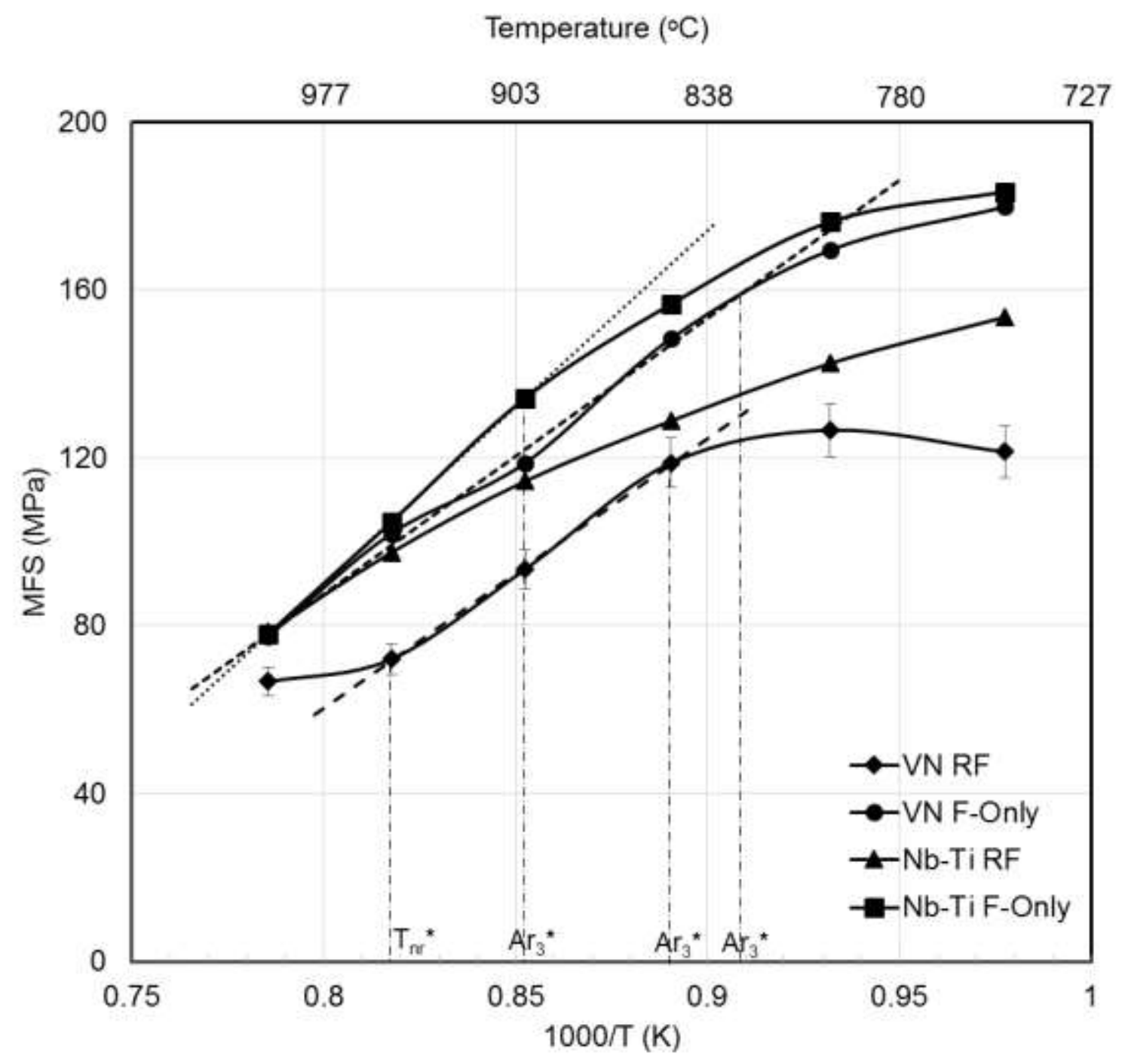

Figure 4 - Typical Boratto diagrams for both $\mathrm{VN}$ and $\mathrm{Nb}$-Ti steels

Onset of DT and DRX: The onset of DT and DRX is characterized by the critical strain of DT and DRX, $\varepsilon_{C D T}$ and $\varepsilon_{C D R X}$, and in this study is given by the minima in $\frac{\partial \ln \theta}{\partial \varepsilon}$ versus $\varepsilon$ plots, see Figure 5 which is summarized in Error! Reference source not found.

Error! Reference source not found.

\begin{tabular}{|c|c|c|c|c|c|c|c|}
\hline Steel & Condition & $750^{\circ} \mathrm{C}$ & $800^{\circ} \mathrm{C}$ & $850^{\circ} \mathrm{C}$ & $900^{\circ} \mathrm{C}$ & $950^{\circ} \mathrm{C}$ & $1000^{\circ} \mathrm{C}$ \\
\hline \multirow[b]{2}{*}{ VN } & RF & DT & $\begin{array}{ll}\mathrm{DT} & \mathrm{Q} \\
\mathrm{DRX} & \end{array}$ & $\begin{array}{ll}\mathrm{DT} & \mathrm{\&} \\
\mathrm{DRX} & \end{array}$ & \begin{tabular}{|ll} 
DT & \& \\
DRX &
\end{tabular} & $\begin{array}{ll}\text { DT } & \& \\
\text { DRX }\end{array}$ & DRX \\
\hline & F-only & $\begin{array}{ll}\text { DT } & \& \\
\text { DRX }\end{array}$ & $\begin{array}{ll}\text { DT } & \& \\
\text { DRX } & \\
\end{array}$ & DRX & DRX & DRX & DRX \\
\hline \multirow{2}{*}{$\mathrm{Nb}-\mathrm{Ti}$} & RF & $\begin{array}{ll}\text { DT } & \& \\
\text { DRX } & \end{array}$ & $\begin{array}{ll}\text { DT } & \& \\
\text { DRX } & \\
\end{array}$ & $\begin{array}{l}\text { DT } \\
\text { DRX }\end{array}$ & \begin{tabular}{|ll} 
DT & \& \\
DRX & \\
\end{tabular} & $\begin{array}{ll}\text { DT } & \text { \& } \\
\text { DRX } & \end{array}$ & DT \& DRX \\
\hline & F-only & $\begin{array}{ll}\text { DT } & \text { \& } \\
\text { DRX }\end{array}$ & $\begin{array}{ll}\text { DT } & \& \\
\text { DRX } & \end{array}$ & $\begin{array}{ll}\text { DT } & \& \\
\text { DRX }\end{array}$ & DRX & DRX & DRX \\
\hline
\end{tabular}




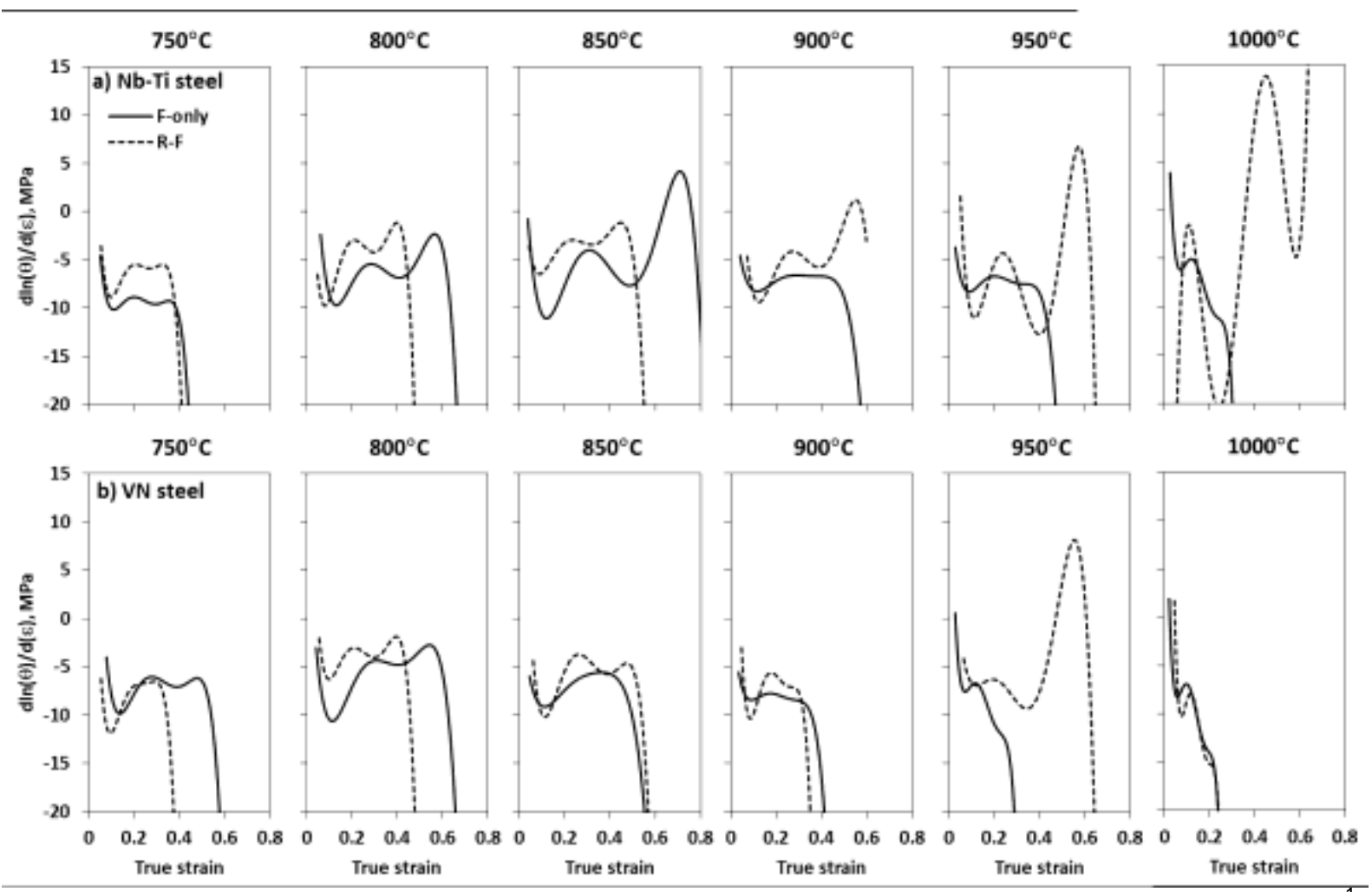

Figure 5 - Plots for the determination of $\varepsilon_{c D T}$ and $\varepsilon_{c D R X}$ for RF and F-only specimens at a $\dot{\varepsilon}=0.1 \mathrm{~s}^{-1}$ a) $\mathrm{Nb}$-Ti steel and b) VN steel. Double minima indicate both softening mechanisms are present and they represent $\varepsilon_{C D T}$ and $\varepsilon_{C D R X}$ respectively. A single minimum indicates $\varepsilon_{C D T}$ at low temperatures or $\varepsilon_{C D R X}$ at high temperatures

As can be observed in Figure 5, as well as Figure 6, for both $\mathrm{VN}$ and $\mathrm{Nb}$-Ti steels, $\varepsilon_{C D T}$ was found to be within the range 0.08 to 0.12 for the RF specimens while for $F$ only specimens $\varepsilon_{C D T}$ was within the range 0.11 and 0.14 . The onset of DRX, $\varepsilon_{C D R X}$, was in the range of 0.30 to 0.45 when both DT and DRX were present, or between 0.06 and 0.11 when DRX was the only softening mechanism present. The effect of temperature on the critical strains was also assessed from $\varepsilon_{c}$ versus temperature plots, Figure 6. It would appear, within experimental scatter, that a nose for $\varepsilon_{C D T}$ was apparent under RF conditions but conspicuously absent in F-only specimens. The nose also coincides with an increase in $\varepsilon_{c D R X}$ as DT is accelerated. 


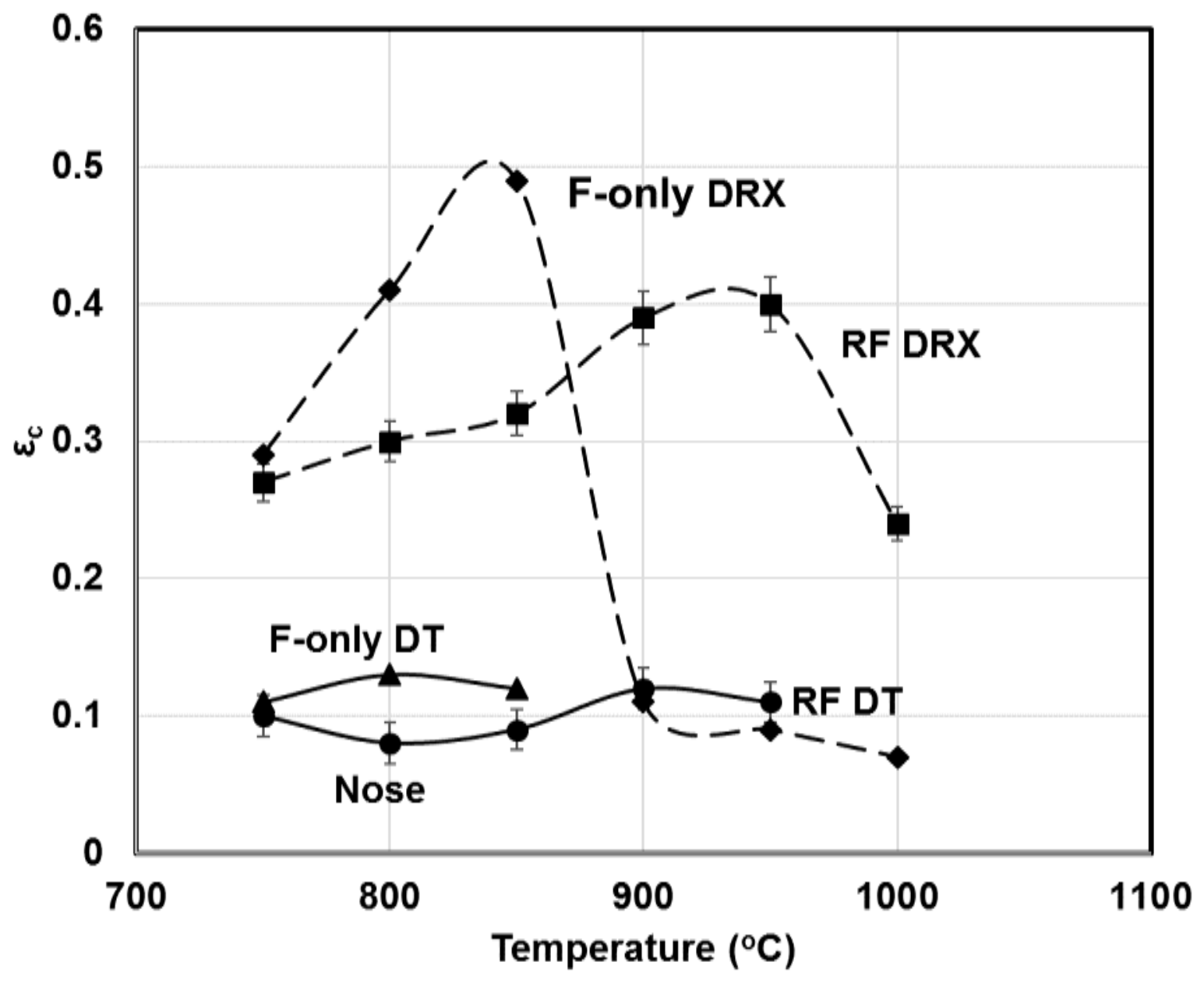

a)

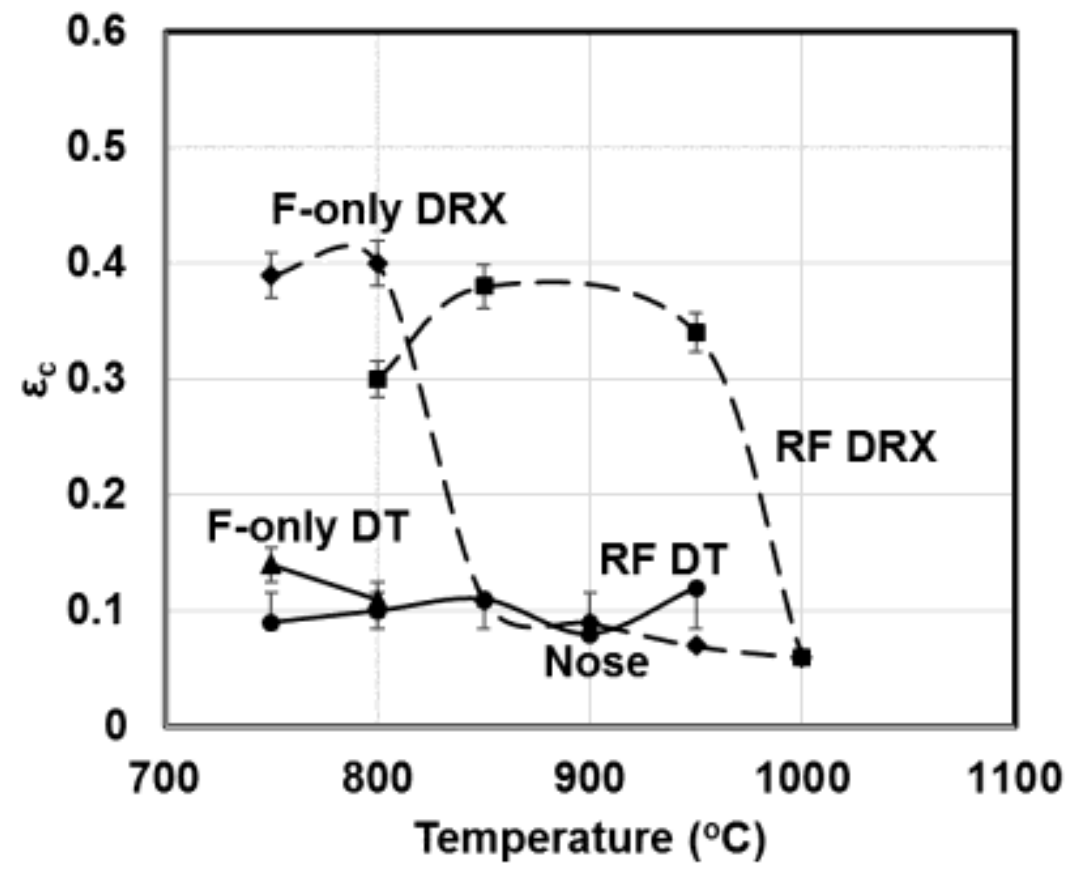

b)

Figure 6 - Schematic plot of $\varepsilon_{c}$ versus temperature for a) VN steel and b) $\mathrm{Nb}$ - Ti steel 


\section{Microstructural observations}

Quantitative analysis of the initial microstructures prior to the finishing pass was done, see Figure 7. The mean Prior Austenite Grains size (PAGS) for VN steel was slightly greater than that of $\mathrm{Nb}$-Ti steel for F-only schedule while for the RF schedule, the mean PAGS for VN steel was lower than that of $\mathrm{Nb}$-Ti steel. Figure 8 shows the optical micrographs for RF and F-only VN steel specimens obtained after deformation schedules in Figure 1. Generally, the transformation products are a ferritic microstructure with Widmanstätten ferrite observed in RF specimens at lower temperatures and fine ferritic grains can be observed along the prior austenitic grains in F-only specimens at the lower temperatures. The F-only microstructures have generally a smaller mean intercept and a higher standard deviation or spread compared to the RF specimens at the same temperature. It can also be observed from the micrographs that RF microstructures are homogenous compared to the Fonly specimens which show a bimodal microstructure of grain size, especially at low temperatures.

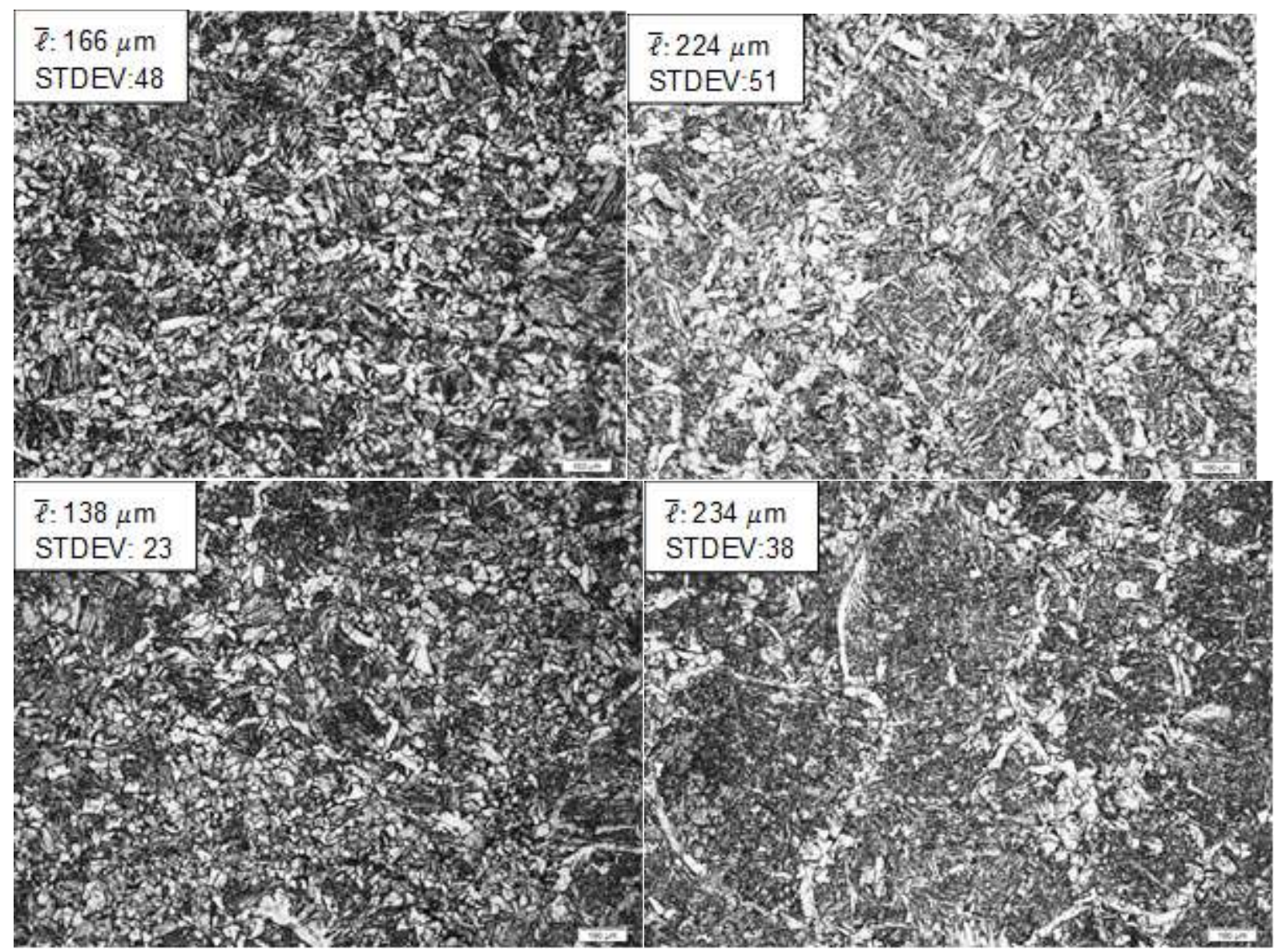

Figure 7 - Micrographs at a magnification of $100 \mu \mathrm{m}$ and their respective Mean Intercept length, $\ell$, showing initial microstructures (Prior Austenite Grains-PAGS) for RF and F-only schedules for a) Fonly VN steel, b) RF VN steel, c) F-only Nb-Ti steel and d) RF Nb-Ti steel 


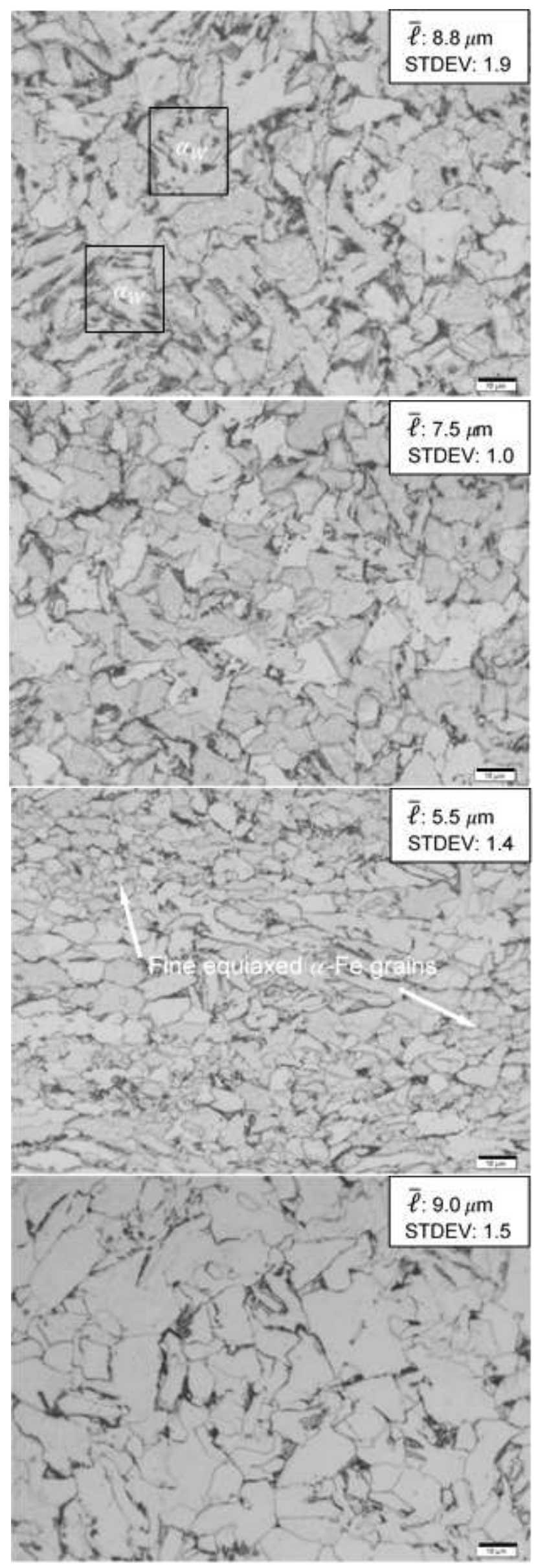




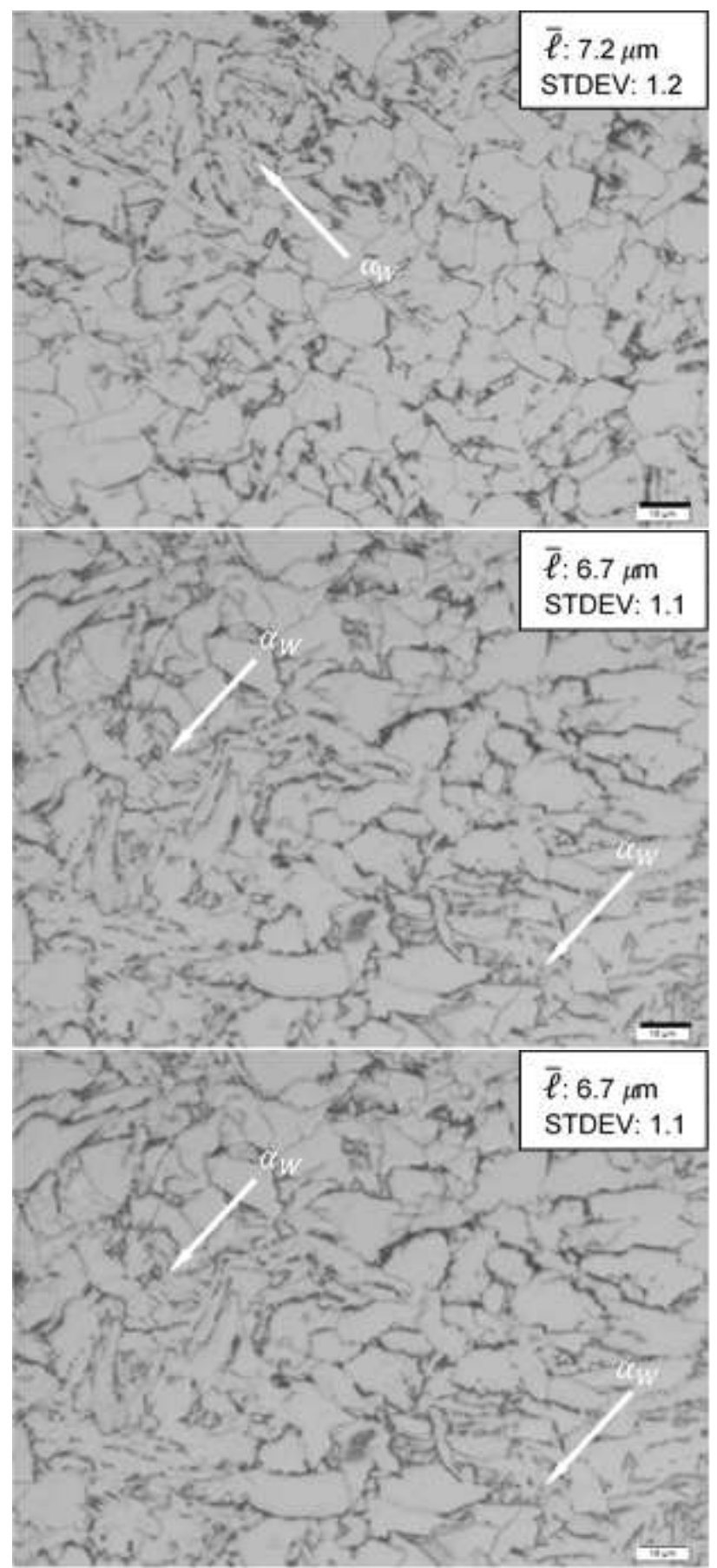

Figure 8 - VN steel micrographs with a scale bar of $10 \mu \mathrm{m}$ and their respective Mean Intercept length $\bar{\ell}$, at varying temperatures for both RF and F-only specimens after deformation as per schedules in 


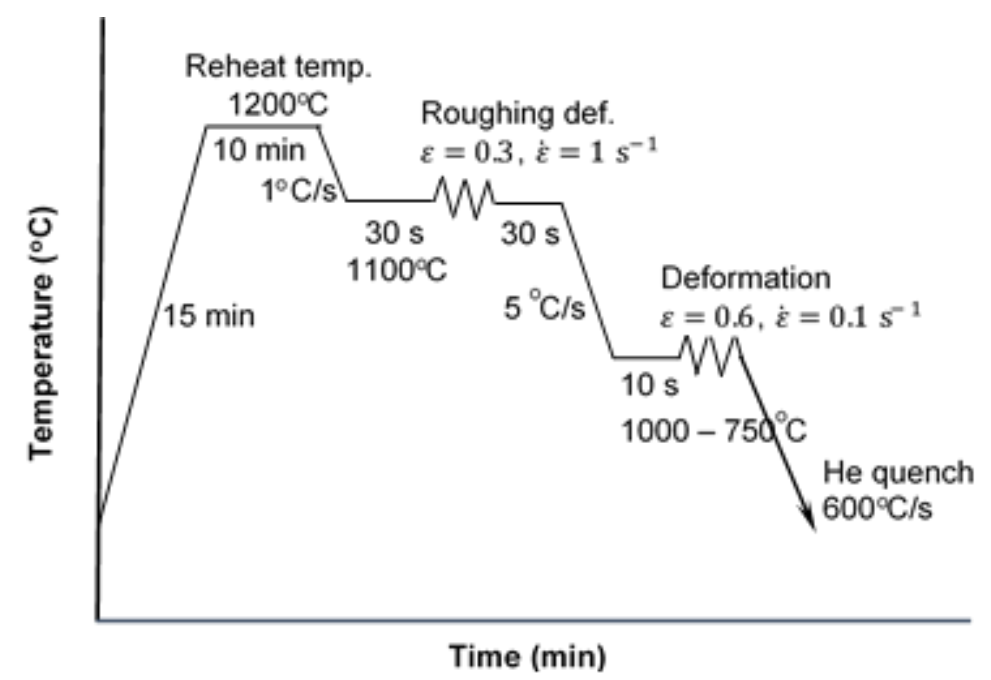

a)

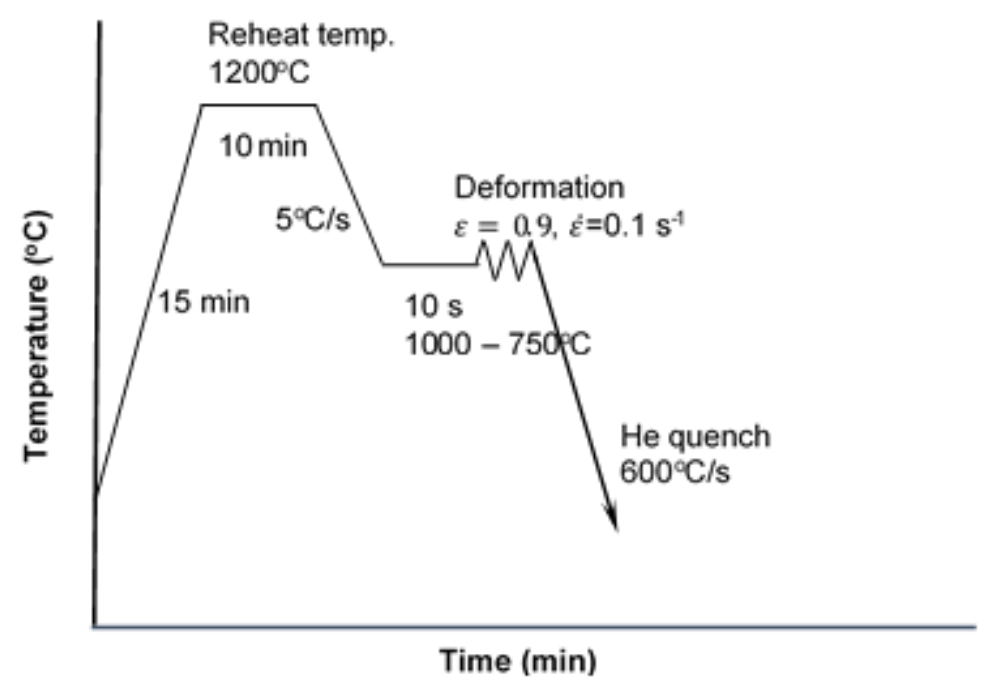

b)

Figure 1. The micrographs are for a) $R F$ deformed at $750{ }^{\circ} \mathrm{C}$, b) $R F$ deformed at $900{ }^{\circ} \mathrm{C}, \mathrm{c}$ ) $\mathrm{RF}$ deformed at $1000^{\circ} \mathrm{C}$, d) F-only deformed at $750^{\circ} \mathrm{C}$, e) F-only deformed at $900^{\circ} \mathrm{C}$, and f) F-only deformed at $1000{ }^{\circ} \mathrm{C}$. Widmanstätten ferrite is indicated as $\alpha_{W}$ in the micrographs.

\section{Discussion}

\section{Effect of roughing pass inclusion on finishing flow curves}

Although the RF specimens were subjected to a finishing true strain of 0.6 compared to 0.9 for F-only specimens in Figure 2, the RF curves had all the characteristics displayed in the F-only curves. The inclusion of a roughing pass did not mask the flow stress curve features in the finishing pass and strain limitation was, therefore, not considered as a constraint in including a roughing pass. Higher stress levels were observed in the F-only flow curves, which may be attributable to the inhomogeneous and coarser initial microstructures since roughing pass conditions the austenite through grain refinement. Higher stress levels for F-only specimens could also contribute to higher flow stress predictions in models based on data that do not include conditioning of austenite. Grain refinement promotes both DRX and DT due to increased nucleation sites i.e. greater grain surface area to volume ratios. 
In Figure 2, the flow stress increases with decreasing temperature in the austenite region for both $\mathrm{RF}$ and F-only schedules. The exception was the VN steel RF schedule at finishing pass temperature of $750{ }^{\circ} \mathrm{C}$, where there was a significant stress drop beyond a strain of 0.3 , comparatively. This may be attributed to DT, since DT is considered favourable at high Zener-Hollomon $(Z)$ values, i.e. low temperatures and high strain rates, compared to $\mathrm{DRX}$, which is dominant at low $Z$ values. Since deformation is applied below the $\mathrm{Ar}_{3}$ temperature in this case, the starting microstructure was determined through differential dilatometry to contain about $85 \%$ austenite. The effect of the statically transformed ferrite fraction during the finish rolling was ruled out as the flow stress was higher up to strain of 0.3 , obeying thermal work-hardening principles of higher flow stress with reducing temperature as evidenced when comparing flow curves at $750{ }^{\circ} \mathrm{C}$ and $800{ }^{\circ} \mathrm{C}$. Although the starting microstructure of the RF Nb-Ti steel was $80 \%$ austenite, greater effects of straininduced precipitation in $\mathrm{Nb}$-Ti steels could explain the increased work-hardening in this case. The maximum stress levels were consistently lower in the VN steel compared to the $\mathrm{Nb}-\mathrm{Ti}$ in RF specimens, Figure 2a) and c), despite the higher $\mathrm{Mn}$ content in the VN steel due to the combined effect of solute strengthening of $\mathrm{Nb}$ and precipitation strengthening of $\mathrm{Nb}(\mathrm{C}, \mathrm{N})$ over $\mathrm{V}(\mathrm{C}, \mathrm{N})$. In Figure $2 \mathrm{~b})$ and $\mathrm{d}$ ), the F-only flow stress magnitude in the $\mathrm{Nb}$-Ti steel was lower than that of $\mathrm{VN}$ steel at $750{ }^{\circ} \mathrm{C}$, comparable at $800^{\circ} \mathrm{C}$ and above $900^{\circ} \mathrm{C}$. The flow stress levels for $\mathrm{Nb}$-Ti were higher than VN steel only at 850 and $900{ }^{\circ} \mathrm{C}$. This points to inhomogeneity of the F-only specimens which may affect modelling of the flow stress if based on the data from $\mathrm{F}$ only route.

On the type of flow stress curves, the type of shape of the flow curves were summarised in Error! Reference source not found. for both RF and F-only specimens. In the literature, the flow curves are generally classified as DRX or DRV type [10] which is misleading as the transition DT/DRX inter-mode regime is regarded as a DRV only regime, i.e. DRV only principles applied where softening due to both DRX and DT also exists. The RF specimens showed the transition (i.e. three distinct regimes) compared to F-only specimens which only showed two regimes at the test temperatures (i.e. DT/DRX inter-mode and DRX regime). It can, therefore, be concluded that the RF specimens were consistent and sensitive to various softening mechanisms at play as the DRX shape was observed at higher temperatures, a DT/DRX inter-mode type at intermediate temperatures and DT shape at lower temperatures as would be expected.

\section{Further analysis of the flow curves}

A systematic analysis was done to identify the softening mechanisms and their effects on $\sigma-\varepsilon$ curves. Firstly, the plot of $\sigma_{p}$ against temperature (see Figure 3) indicated thermal work-hardening with decrease in temperature. However, a significant drop in peak stress at lower temperatures was observed, which provided further evidence of softening attributable to DT. Softening mechanisms were also accelerated in RF specimens as may be observed in the negative increase in $\sigma_{p}$ for temperatures below $850{ }^{\circ} \mathrm{C}$. Comparatively, DT is favourable at lower temperature while DRX is dominant at high temperatures. DT softening occurring at temperatures between 750 and $850{ }^{\circ} \mathrm{C}$ is significantly high in $\mathrm{RF}$ specimens due to grain refinement which increased both nucleation sites and nucleation rates. In a hot rolling process, softening due to DT would therefore lower the mill loads especially in the final passes of finish rolling where deformation temperatures are lower. 
Secondly, evidence of work-hardening, recrystallization, and transformation in hot rolling is given by the evolution of the mean flow stress (MFS) and is evaluated by Boratto diagrams [21]. The Boratto diagrams, as given in Figure 4, confirmed extensive softening especially at temperatures of 750 and $800{ }^{\circ} \mathrm{C}$ in RF specimens. The Boratto diagrams were also used to determine the upper critical temperatures for deformed austenite $\mathrm{Ar}_{3}^{*}$, given in Error! Reference source not found. [20]. It can be observed that for the RF curves in Figure 4, $A r_{3}^{*}$ is higher than the $A e_{3}$ temperature, giving evidence that DT can take place at temperatures higher than the $A e_{3}$ temperature while for F-only specimens the $A r_{3}^{*}$ temperatures were lower than the $\mathrm{Ae}_{3}$ temperatures. This may be due to inhomogeneity in the specimen and grain size effects leading to lower $A r_{3}^{*}$ temperatures.

Higher peak stress and MFS values were obtained for the Nb-Ti steel compared to the VN steel. This pointed to the strong precipitation strengthening effect of Niobium when compared to the solute drag effect of Vanadium over the deformation conditions given in Figure 1. The $\mathrm{Nb}$-Ti steel also had higher transformation temperatures, comparatively. The consequence of this is that DT can be observed at higher temperatures typical of the hot strip rolling process and may lead to mill load fluctuations generally experienced in hot rolling of $\mathrm{Nb}-\mathrm{Ti}$ steels. Secondly, partial transformation and recrystallization results in inhomogeneous microstructures affecting the final properties of the $\mathrm{Nb}$-Ti steels.

The apparent nil-recrystallization temperature $\left(T_{n r}{ }^{*}\right)$, was determined for the VN steel RF specimens. Boratto diagrams for RF specimens were, therefore, able to distinguish between the various critical temperatures compared to F-only specimens that were only able to detect the transformation start temperatures, i.e. other critical temperatures were obscured. For Nb-Ti steels, however, only the $A r_{3}^{*}$ is determined as a higher apparent $T_{n r}{ }^{*}$ is expected beyond the temperature range considered under this study. Lastly, there was more scatter in the MFS data obtained for F-only specimens in Figure 4 due to inconsistencies in the starting microstructure that could affect the MFS and microstructural evolution models developed compared to models based on data from RF specimens.

\section{Critical strains for DT and DRX}

Observations from a summary of the critical strains $\left(\varepsilon_{c}\right)$ for DT given in Figure 6 indicates that $\varepsilon_{C D T}$ was within the range 0.08 to 0.12 for the RF specimens, which is in agreement with the $\varepsilon_{C D T}$ values reported in the literature in the range of 0.05 to $0.12[18,22]$ while for F-only specimens, $\varepsilon_{c D T}$ was in the range of 0.11 to 0.14 . Lower $\varepsilon_{C D T}$ in RF specimens could be due to the finer and more uniform grains which promote DT softening compared to the F-only specimens. Despite the increase in nucleation rate characterised by the nose, as reported by Aranas et al. [19, 14], $\varepsilon_{c} D T$ was not significantly affected with temperature increases. This is attributed to the athermal displacive formation and growth of dynamically transformed Widmanstätten ferrite. The Widmanstätten ferrite plates gradually coalesce into polygonal grains during continued deformation.

For F-only specimens in Figure 5, DT was present at temperatures of between 750 and $800{ }^{\circ} \mathrm{C}$ (i.e. below $\mathrm{Ae}_{3}$ ) while in RF specimens, DT occurred up to $950{ }^{\circ} \mathrm{C}$ for $\mathrm{VN}$ steel and $1000{ }^{\circ} \mathrm{C}$ for $\mathrm{Nb}$-Ti steel which is about $117^{\circ} \mathrm{C}$ and $133 \pm 25^{\circ} \mathrm{C}$ above the $\mathrm{Ae}_{3}$, respectively. This difference highlights the challenge in most flow stress models based on F-only deformation schedules in the literature which overestimates flow 
stresses in low temperature work-hardened austenite as the softening effects of DT are neglected. It should be noted that $\mathrm{NbTi}(\mathrm{C}, \mathrm{N})$ precipitates in $\mathrm{Nb}-\mathrm{Ti}$ steel inhibits recrystallization due to Zener pinning effect. On the other hand, the precipitates promoted dynamic transformation in the $\mathrm{Nb}-\mathrm{Ti}$ steel compared to the $\mathrm{VN}$ steel as they became preferential nucleation sites and limited the solute drag effect on the transformation front.

Another controversy in the literature is whether recrystallization or recovery takes place in ferrite. It can be seen from Figure 5 and Error! Reference source not found. that at $750{ }^{\circ} \mathrm{C}$, the F-only specimen indicates the occurrence of both DT and DRX while RF specimens indicate only DT taking place. This anomaly could be attributed to the recrystallization of the residual austenite in the F-only specimens which gives a false impression of the presence of DRX in ferrite. The analysis of Fonly data would therefore be misleading as recovery followed by strain partitioning in ferrite and austenite leads to more DT of the remaining austenite. Recrystallization in ferrite takes place though continuous DRX (cDRX) which is dominant at exceedingly higher strains as recovery is favoured in ferrite [23, 24]. Although within experimental data scatter, the nose in the $\varepsilon_{c}$ versus temperature curves in Figure 6 is in agreement with findings by Ghosh [20]. The RF specimen plots signify that the formation of DT ferrite is accelerated in the vicinity of the nose temperature (i.e. indicating an optimum driving force for the DT) which is similar in concept to the nose temperature found in CCT diagrams. For F-only specimens the nose was not detected which could affect modelling of DT kinetics or DT mechanisms studies. The nose was also synonymous with retardation of DRX as it coincided with an increase in $\varepsilon_{C D R X}$. It is considered that accelerated DT around the nose retards onset of DRX since the two softening mechanisms compete for the same favourable nucleation sites.

\section{Prior Austenite Grain size in RF and F-only schedules}

Micrographs showing the Prior Austenite Grain sizes (PAGS) given in Figure 7 were quantified using computer image analysis techniques and indicate was observed.

F-only: The VN steel had a slightly larger PAGS (mean intercept length, $\bar{\ell}=234 \mu \mathrm{m}$ and Standard Deviation, SD=38) compared to Nb-Ti steel $(\bar{\ell}=224 \mu \mathrm{m}, \mathrm{SD}=51)$. This could be due to pinning of the grains during austenitization by $\mathrm{NbTi}(\mathrm{C}, \mathrm{N})$ which comparatively has higher dissolution temperatures. It should also be noted that the standard deviation was greater in $\mathrm{Nb}$ - Ti steels which could be attributed to non-even pinning effect of the $\mathrm{NbTi}(\mathrm{C}, \mathrm{N})$. However, the values were comparable considering the standard deviations.

RF: After the roughing pass, the PAGS for VN steel was $138 \mu \mathrm{m}$ while for $\mathrm{Nb}$-Ti steel was $166 \mu \mathrm{m}$. This could be due to the $\mathrm{NbTi}(\mathrm{C}, \mathrm{N})$ precipitates which may inhibit recrystallization in the $\mathrm{Nb}$-Ti steel. As experimentally validated by Zheng et al. [25], larger PAGS is associated with higher volume of intragranular deformation defects for a given set of deformation conditions. The high intragranular energy defects in coarser $\mathrm{VN}$ steel are the driving force for recrystallization in compared to the $\mathrm{Nb}-\mathrm{Ti}$ steel. There was a bigger variation in grain sizes in $\mathrm{Nb}-\mathrm{Ti}$ steel $(\mathrm{SD}=48)$ compared to $\mathrm{VN}$ steel $(\mathrm{SD}=23)$. However, when compared to F-only structures, the RF microstructures were more uniform leading to consistent initial conditions during the tests. 
It should be noted that although $\mathrm{NbTi}(\mathrm{C}, \mathrm{N})$ precipitates inhibit recrystallization, dynamic transformation on the other hand is enhanced by precipitates as they act as preferential nucleation sites and also decreases the solute drag effect on the transformation front during transformation.

\section{Effect of roughing on final microstructures}

Low carbon $\mathrm{VN}$ and $\mathrm{Nb}$ - $\mathrm{Ti}$ microalloyed steels have a low hardenability and in most cases cooling is interrupted during coiling at intermediate temperatures, leading to ferrite as the target microstructure. Ferrite, therefore, forms the final microstructure matrix for VN steels, Figure 8 and also for Nb steels (not shown here).

F-only: Most analyses of dynamically transformed microstructures are based on compression testing of F-only specimens, where a bimodal distribution of very fine equiaxed DT grains nucleated along the prior austenite grain boundaries and statically transformed coarse grains are reported as proof of DT [12, 10, 11]. A bimodal grain size distribution accompanied with a higher standard deviation can be observed in Figure $7 \mathrm{~d}$ ) for F-only specimens at $750^{\circ} \mathrm{C}$ and also at $800{ }^{\circ} \mathrm{C}$ (not shown here). The coarse ferrite grains have a deformed pancaked shape that indicates they are from work-hardened austenite and are not a direct result of the conventional nucleation during the static or annealing transformation process. It is considered that the dislocations introduced during straining of F-only specimens have a heterogeneous distribution leading to a bimodal distribution of very fine equiaxed grains transformed dynamically, and the conventional coarse ferrite that is transformed statically during the annealing or quenching processes [11, 12]. This leads in most cases to the conclusion that DT is present only between the $\mathrm{Ae}_{3}$ and $\mathrm{Ar}_{3}$ temperatures where the driving force for DT is highest [11] and that DT leads to an inhomogeneous grain structure [10] as can be observed in this case.

$\boldsymbol{R F}$ : DT takes place even at temperatures above $\mathrm{Ae}_{3}$. From the analysis of $\varepsilon_{c}$, DT is present in conditioned specimens up to $950^{\circ} \mathrm{C}$ which is about $117^{\circ} \mathrm{C}$ above the $\mathrm{Ae}_{3}$ temperature of $833^{\circ} \mathrm{C}$ for VN steel. Grain size inhomogeneity in F-only specimens affect both the initiation of DT and DRX. Conditioning of austenite through a roughing pass, therefore, plays a critical role in studying microstructural evolution during deformation, determination of the critical strains and modelling of softening mechanism kinetics which are based on softening volume fractions.

From Figure 8a) to b), it can also be observed that the RF microstructures have a more homogeneous ferrite morphology with islands of Widmanstätten ferrite which indicates that the DT is an athermal para-equilibrium displacive transformation [14]. The displacive transformation is followed by coalescence of the Widmanstätten ferrite plates into equiaxed ferrite grains upon further deformation. The morphology of DT ferrite is mainly affected by the undercooling together with hardenability of the steel with equiaxed ferrite being precipitated at small undercooling or Widmanstätten plates if precipitated at large undercooling [25]. This is in contrast to the static Widmanstätten ferrite associated with coarse austenite that normally nucleates on the allotriomorphic ferrite as observed in F-only specimens at $1000^{\circ} \mathrm{C}$, 


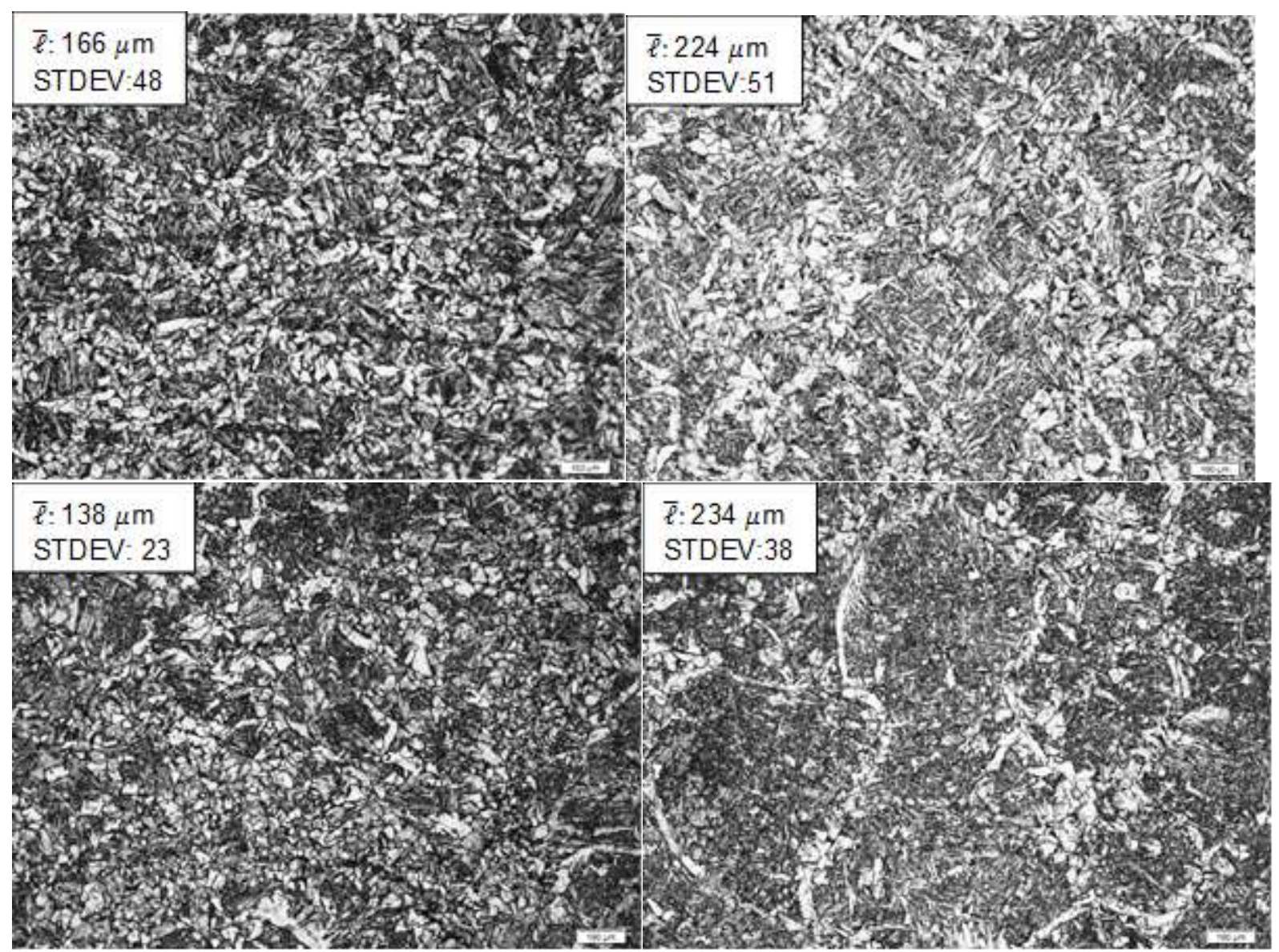

Figure 7 - Micrographs at a magnification of $100 \mu \mathrm{m}$ and their respective Mean Intercept length, $\ell$, showing initial microstructures (Prior Austenite Grains-PAGS) for RF and F-only schedules for a) Fonly VN steel, b) RF VN steel, c) F-only Nb-Ti steel and d) RF Nb-Ti steel 


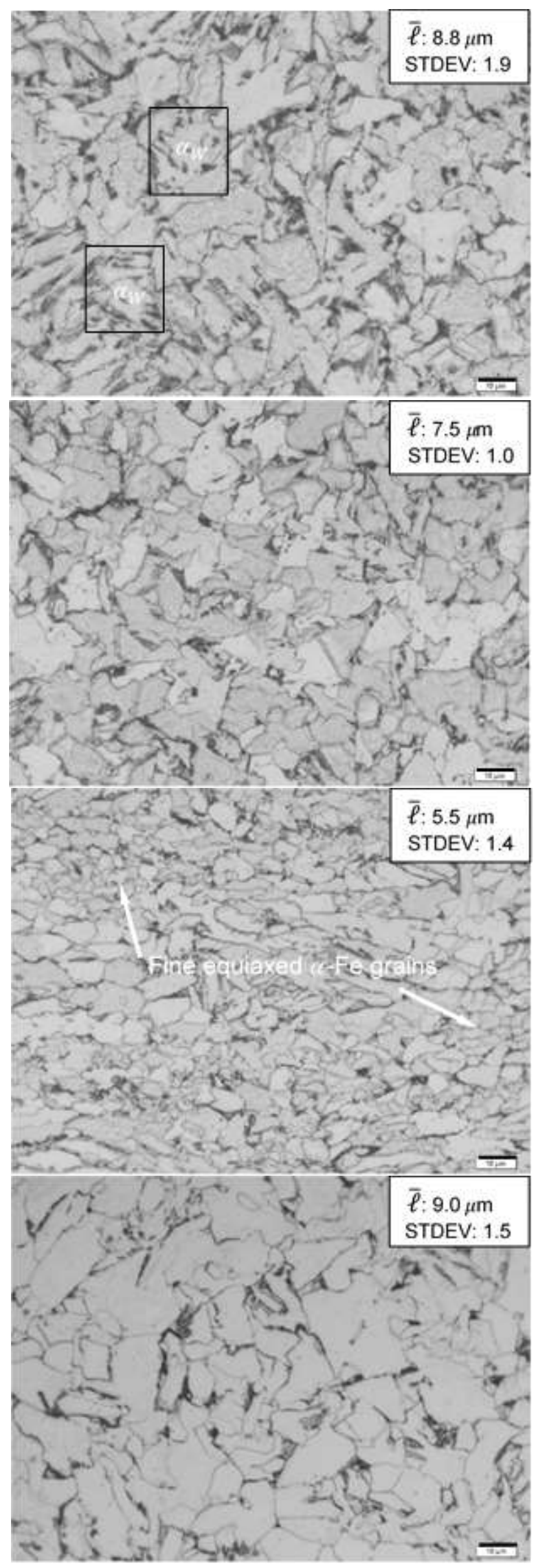




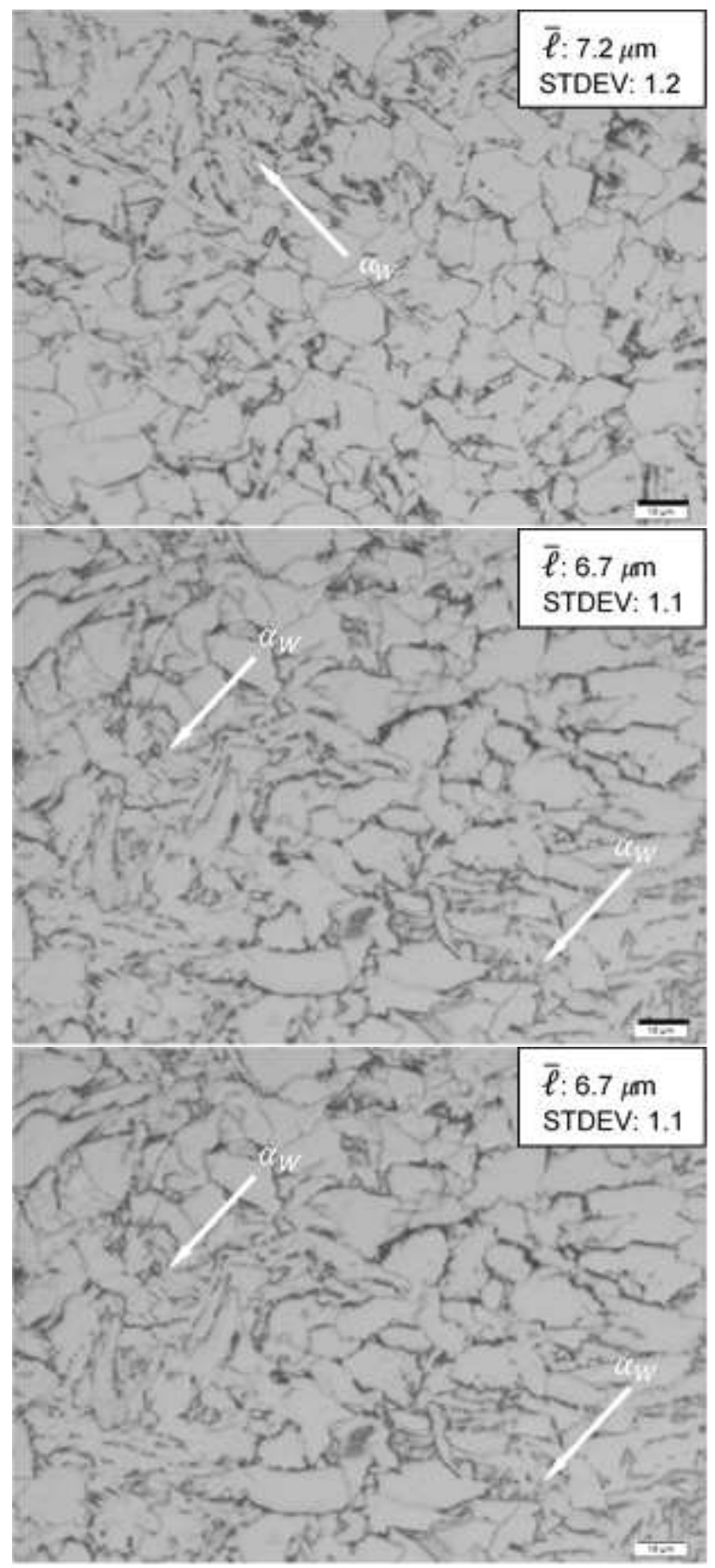

Figure 8f). The finer prior austenite grain microstructure in RF specimens increases ferrite nucleation sites and promotes DT and DRX as it lowers their respective $\varepsilon_{c}$. Higher nucleation rates also suppress grain growth, leading to homogeneous grain refinement. The smoothly curved interfaces of most of the ferrite grains indicates grain growth after the displacive transformation and coalescence of the plates [14, 25]. This dynamic and static growth leads to the final microstructure observed in the RF micrographs. Another observation from the micrographs in Figure 8 is the finer grains obtained at deformation temperatures where DT only is present compared to when DRX only is present, i.e. at 750 and $1000{ }^{\circ} \mathrm{C}$, respectively. This would mean that grain refinement through DT has a potential in microalloyed steels.

It should be noted, however, that the dynamically formed microstructure is highly sensitive to quenching and/or annealing due to low stability of deformed low carbon 
austenite. A suitable quenching technique should, therefore, be considered that would preserve the deformed microstructure when studying DT and DRX.

\section{Conclusion}

The following influences of roughing and finishing passes (RF) over Finishing only (Fonly) on flow stress curves, softening mechanisms and microstructural morphology have been established:

1) The RF schedule gave more reliable and consistent flow stress data that promotes accuracy in modelling of rolling forces or Mean Flow Stress

2) Greater consistencies and accuracy in softening mechanisms transitions thereby promoting accuracy in modelling of softening kinetics in the DT regime for temperatures below $800{ }^{\circ} \mathrm{C}$, DT/DRX inter-mode regime between 800 and $950{ }^{\circ} \mathrm{C}$ and DRX regime for temperatures above $950^{\circ} \mathrm{C}$ for $\mathrm{VN}$ steel

3) Roughing promoted softening mechanisms as evidenced by lower $\varepsilon_{C D T}$ which was within the range 0.08 to 0.12 for the roughing and finishing schedules while for Finishing pass only, the $\varepsilon_{C D T}$ was in the range of 0.11 to 0.14 .

4) RF schedules verified the presence of DT at temperatures of about $117{ }^{\circ} \mathrm{C}$ and $133^{\circ} \mathrm{C}$ above $\mathrm{Ae}_{3}$ for $\mathrm{VN}$ steel and $\mathrm{Nb}$-Ti steel, respectively, while the $\mathrm{F}$ only schedules showed DT only takes place at temperatures between $\mathrm{Ar}_{3}$ and $\mathrm{Ae}_{3}$.

5) More consistent microstructural morphologies with uniform grain size distribution was observed after roughing and finishing passes that could reliably be used as a basis of microstructural evolution models compared to inhomogeneous microstructure after finishing only pass.

\section{Acknowledgements}

This work has been performed with funding from the University of Pretoria and technical support from Industrial Minerals and Metals Research Institute (IMMRI). Help from Rorisang Maubane is gratefully acknowledged for providing on-equipment training and technical support on the Bähr $850 \mathrm{AD}^{\mathrm{TM}}$ and Gleeble $1500^{\mathrm{TM}}$ tests. 


\section{References}

[1] D. Samantaray, S. Mandal and A. K. Bhaduri, "A comparative study on Johnson Cook, modified Zerilli-Armstrong and Arrhenius-type constitutive models to predict elevated temperature flow behaviour in modified 9Cr-1Mo steel," Computational Materials Science, vol. 47, pp. 568-576, 2009.

[2] B. Roebuck, J. D. Lord, M. Brooks, M. S. Loveday, C. M. Sellars and R. W. Evans, "Measurement of flow stress in hot axisymmetric compression tests," Science Reviews Materials at High Temperatures, vol. 23, no. 2, pp. 59-83, 2006.

[3] R. Ebrahimi and E. Shafiei, "Mathematical Modeling of Single Peak Dynamic Recrystallization Flow stress curves in Metallic alloys," 2012. [Online]. Available: http://www.intechopen.com/books/recystallization/mathematical-modelling-of-sinlgepeak-dynamic-recrystallization-flow-stress-curves-in-metallic-alloys. [Accessed 30 May 2015].

[4] S. K. Rajput, G. P. Chaudhari and S. K. Nath, "Physical Simulation of Hot Deformation of Low-Carbon Ti-Nb Microalloyed Steel and Microstructual Studies," Journal of Materials Engineering and Performance, vol. 23, no. 8, pp. 2930-2942, 2014.

[5] B. Eghbali, "Effect of strain rate on the microstructural development through continuous dynamic recrystallization in a microalloyed steel," Materials Science and Engineering A, vol. 527, pp. 3402-3406, 2010.

[6] H. Beladi and P. D. Hodgson, "Effect of carbon content on the recrystallization kinetics of Nb-steel," Scripta Materialia, vol. 56, pp. 1059-1062, 2007.

[7] P. D. Hodgson and R. K. Gibbs, "A Mathematical Model to Predict the Mechanical Properties of Hot Rolled C-Mn and Microalloyed Steels," ISIJ International, vol. 32, no. 12, pp. 1329-1338, 1992.

[8] P. D. Hodgson, S. H. Zahiri and J. J. Whale, "The Static and Metadynamic Recrystallization Behaviour of an X60 Nb Microalloyed Steel," ISIJ International, vol. 44, no. 7, pp. 1224-1229, 2004.

[9] S. H. Zahiri, S. M. Byon, S. Kim, Y. Lee and P. D. Hodgson, "Static and metadynamic recrystallization of Interstitial Free steels during hot deformation," ISIJ International, vol. 44, no. 11, pp. 1918-1923, 2004.

[10] B. Eghbali and A. Abdollah-zadeh, "Influence of deformation temperature on the ferrite grain refinement in a low carbon $\mathrm{Nb}-\mathrm{Ti}$ microalloyed steel," Journal of Materials Processing Technology, vol. 180, pp. 44-48, 2006.

[11] J.-K. Choi, D.-H. Seo, J.-S. Lee, K.-K. Um and W.-Y. Choo, "Formation of Ultrafine Ferrite by Strain-induced Dynamic Transformation in Plain Low Carbon Steel," ISIJ International, vol. 43, no. 5, pp. 746-754, 2003.

[12] H. Dong and X. Sun, "Deformation induced ferrite transformation in low carbon steels," Current Opinion in Solid State and Materials Science, vol. 9, pp. 269-276, 2005.

[13] $\mathrm{H}$. Mirzadeh and A. Najafizadeh, "Prediction of the critical condition for initiation of Dynamic Recrystallization," Materials Design, vol. 31, pp. 1174-1179, 2010.

[14] C. J. Aranas, T. Nguyen-Minh, R. Grewal and J. J. Jonas, "Flow Softening-based Formation of Widmanstatten Ferrite in a $0.06 \%$ C Steel Deformed Above the Ae3," ISIJ International, vol. 55, no. 1, pp. 300-307, 2015.

[15] J. Biglou and J. G. Lenard, "A Study of Dynamic Recrystallization During Hot Rolling of Microalloyed Steels," Annals of the CIRP, vol. 45, no. 1, pp. 227-230, 1996.

[16] S. F. Medina and V. Lopez, "Static Recrystallization in Austenite and Its Influence on 
Microstructural Changes in C-Mn Steel and Vanadium Microalloyed Steel at the Hot Strip Mill," ISIJ International, vol. 33, no. 5, pp. 605-614, 1993.

[17] E. I. Poliak and J. J. Jonas, "A one-parameter approach to determining the critical conditions for the initiation of dynamic recrystallization," Acta mater., vol. 44, no. 1, pp. 127-136, 1996.

[18] J. J. Jonas, C. Ghosh, X. Quelennec and V. V. Basabe, "The Critical Strain for Dynamic Transformation in Hot Deformed Austenite," ISIJ International, vol. 53, no. 1, pp. 145151, 2013.

[19] C. J. Aranas, R. Grewal, K. Chadha, D. Shahriari, M. Jahazi and J. J. Jonas, "Formation of widmanstatten ferrite in a C-Mn steel at temperatures high in the austenite phase field," in Proceedings of the International Conference on Solid-Solid Phase Transformations in Inorganic Materials 2015, 2015.

[20] C. Ghosh, "The Dynamic Transformation of Deformed Austenite at Temperatures above the Ae3," PHd Thesis, McGill University, Montreal, Canada, 2013.

[21] C. J. Aranas, S. F. Rodrigues, R. Grewal and J. J. Jonas, "Ferrite Formation above the Ae3 Temperature during the Torsion Simulation of Strip Rolling," ISIJ International, vol. 55, no. 11, pp. 2426-2434, 2015.

[22] J. J. Jonas, C. J. Aranas and S. F. Rodrigues, "Dynamic Transformation During the Torsion Simulation of Plate and Strip Rolling," Proceedings of the 4th International Conference on Thermo-mechanical Simulation and Processing of Steel, Vols. Ranchi, India, 10-12 February 2016.

[23] T. Sakai, A. Belyakov, R. Kaibyshev, H. Miura and J. J. Jonas, "Dynamic and postdynamic recrystallization under hot, cold and severe plastic deformation conditions," Progress in Materials Science, vol. 60, pp. 130-207, 2014.

[24] M. E. Kassner and S. R. Barrabes, "New developments in geometric dynamic recrystallization," Materials Science and Engineering A, Vols. 410-411, pp. 152-155, 2005.

[25] C. Zheng, N. Xiao, L. Hao, D. Li and Y. Li, "Numerical simulation of dynamic straininduced austenite-ferrite transformation in a low carbon steel," Acta Materialia, vol. 57, pp. 2956-2968, 2009.

[26] L. Du, C. Zhang, H. Ding, X. Liu and G. Wang, "Determination of Upper Limit Temperature of Strain-induced Transformation of Low Carbon Steels," ISIJ International, vol. 42, no. 10, pp. 1119-1124, 2002. 